\title{
The geological nature of dark material on Vesta and implications for the subsurface structure
}

\author{
R. Jaumann ${ }^{\mathrm{a}, \mathrm{b}, *}$, A. Nass ${ }^{\mathrm{a}}$, K. Otto ${ }^{\mathrm{a}}$, K. Krohn ${ }^{\mathrm{a}}$, K. Stephan ${ }^{\mathrm{a}}$, T.B. McCord ${ }^{\mathrm{c}}$, D.A. Williams ${ }^{\mathrm{d}}$, C.A. Raymond ${ }^{\mathrm{e}}$, \\ D.T. Blewett ${ }^{\mathrm{f}}$, H. Hiesinger ${ }^{\mathrm{g}}$, R.A. Yingst ${ }^{\mathrm{h}}$, M.C. De Sanctis ${ }^{\mathrm{i}}$, E. Palomba ${ }^{\mathrm{i}}$, T. Roatsch ${ }^{\mathrm{a}}$, K.-D. Matz ${ }^{\mathrm{a}}$, \\ F. Preusker ${ }^{\mathrm{a}}$, F. Scholten ${ }^{\mathrm{a}}$, C.T. Russell ${ }^{\mathrm{j}}$ \\ ${ }^{a}$ DLR, Inst. of Planetary Research, Berlin, Germany \\ ${ }^{\mathrm{b}}$ Freie Universitaet Berlin, Inst. of Geosciences, Berlin, Germany \\ ${ }^{\mathrm{c}}$ Bear Fight Institute, Winthrop, WA 98862, USA \\ d Arizona State University, Tempe, AZ 85287, USA \\ e Jet Propulsion Laboratory, California Institute of Technology, Pasadena, CA 91109-8099, USA \\ ${ }^{\mathrm{f}}$ Johns Hopkins University Applied Physics Laboratory, Laurel, MD 20723, USA \\ ${ }^{\mathrm{g}}$ Inst. für Planetologie, Westfaelische Wilhelms-Universitaet, Germany \\ h Planetary Science Institute, Tucson, AZ 85719, USA \\ ${ }^{\mathrm{i}}$ Istituto di Astrofisica e Planetologia Spaziali, INAF, Rome, Italy \\ jUCLA, Los Angeles, CA 90096-1567, USA
}

\section{A R T I C L E I N F O}

\section{Article history:}

Received 1 July 2013

Revised 17 April 2014

Accepted 17 April 2014

Available online $\mathrm{xxxx}$

\section{Keywords:}

Asteroid Vesta

Geological processes

Cratering

\begin{abstract}
A B S T R A C T
Deposits of dark material appear on Vesta's surface as features of relatively low-albedo in the visible wavelength range of Dawn's camera and spectrometer. Mixed with the regolith and partially excavated by younger impacts, the material is exposed as individual layered outcrops in crater walls or ejecta patches, having been uncovered and broken up by the impact. Dark fans on crater walls and dark deposits on crater floors are the result of gravity-driven mass wasting triggered by steep slopes and impact seismicity. The fact that dark material is mixed with impact ejecta indicates that it has been processed together with the ejected material. Some small craters display continuous dark ejecta similar to lunar dark-halo impact craters, indicating that the impact excavated the material from beneath a higher-albedo surface. The asymmetric distribution of dark material in impact craters and ejecta suggests non-continuous distribution in the local subsurface. Some positive-relief dark edifices appear to be impact-sculpted hills with dark material distributed over the hill slopes. Dark features inside and outside of craters are in some places arranged as linear outcrops along scarps or as dark streaks perpendicular to the local topography. The spectral characteristics of the dark material resemble that of Vesta's regolith. Dark material is distributed unevenly across Vesta's surface with clusters of all types of dark material exposures. On a local scale, some craters expose or are associated with dark material, while others in the immediate vicinity do not show evidence for dark material. While the variety of surface exposures of dark material and their different geological correlations with surface features, as well as their uneven distribution, indicate a globally inhomogeneous distribution in the subsurface, the dark material seems to be correlated with the rim and ejecta of the older Veneneia south polar basin structure. The origin of the dark material is still being debated, however, the geological analysis suggests that it is exogenic, from carbon-rich low-velocity impactors, rather than endogenic, from freshly exposed mafic material or melt, exposed or created by impacts.
\end{abstract}

(c) 2014 Elsevier Inc. All rights reserved.

\section{Introduction}

Albedo differences on 4 Vesta's surface were observed in multispectral images obtained by the Hubble Space Telescope (Zellner et al., 1997; Binzel et al., 1997; Gaffey, 1997). However, regions

\footnotetext{
* Corresponding author at: DLR, Inst. of Planetary Research, Berlin, Germany.

E-mail address: ralf.jaumann@dlr.de (R. Jaumann).
}

of very low albedo on Vesta's surface were first discovered by the Dawn mission (Jaumann et al., 2012a; Russell et al., 2012; McCord et al., 2012; Reddy et al., 2012). These dark material deposits are non-randomly distributed over the surface and often associated with geological/morphological features (Jaumann et al., 2012b; McCord et al., 2012). Dark material occurs most conspicuously in small, well-defined deposits. These are often but not always directly associated with impact structures and occur in 
crater walls or are excavated by the impact process and mixed into the ejecta. Alternatively, it may occur as blocky or layered outcrops in crater walls and as mass-wasting deposits on crater flanks and floors. One apparent conclusion from these observations (Jaumann et al., 2012b; McCord et al., 2012; Reddy et al., 2012) is that the nature of the dark material deposits, whatever their sources, is strongly influenced by impact mixing, gardening and mass-wasting. In addition to the small, well-defined dark material deposits, there are also large regions of low albedo surface material, often with indistinct boundaries, that appear to include dark material. Intermediate-scale evidence of mixing also exists in the form of wispy and mottled dark material deposits. Data from the Dawn visible and infrared imaging spectrometer (VIR) (De Sanctis et al., 2012a, 2013; Stephan et al., 2014; Palomba et al., 2014) show that the reflectance spectrum of dark material is similar to, but more muted than, the average Vesta spectrum, and contains no obvious additional spectral features. The pyroxene absorptions near 1 and $2 \mu \mathrm{m}$ are present, but attenuated compared to average Vesta surfaces. Typically, dark material deposits show a lower visual to near-IR albedo, with stronger thermal emission because of higher temperatures due to lower albedo (De Sanctis et al., 2012a, 2013; Capria et al., 2014). Dark material may be present as intimate and/or macroscopic mixtures with other Vesta materials. Most regions on Vesta can be modeled as a linear mixture of just two materials, i.e. a bright, pyroxene-rich soil and a generic darker, reddish material (McCord et al., 2012). The dark component does not change the main spectral parameter values, as indicated by the analysis of the band centers and the band depths (Stephan et al., 2014; Palomba et al., 2014).

The main hypotheses formulated so far for the origin of dark material are: (1) low velocity infall from objects containing dark material, (2) basalt flows, dikes or sills on/in Vesta that were broken and redistributed by impacts, and (3) impact melt from major cratering events (McCord et al., 2012; Jaumann et al., 2012a). Dawn images provide no conclusive evidence of basaltic lava flows (Jaumann et al., 2012a; Yingst et al., 2014; Williams et al., 2013), and the evidence of basaltic intrusions is equivocal. In addition, it is difficult to understand how a Vesta-like object could retain sufficient heat to create secondary melting and near-surface extrusions of lava late enough in Vesta's evolution for the flows or major parts of them to survive impact battering into the present day (e.g. Zuber et al., 2011; McSween et al., 2011; Russell et al., 2012, 2013). On the other hand, there is morphological evidence of impact melt deposits on Vesta that have low reflectance (Denevi et al., 2012; Yingst et al., 2014; Williams et al., 2013). Although this is consistent, with the apparent active impact history of Vesta, which must have included some higher-velocity impactors (O'Brien et al., 2011) only one impact melt deposit in crater Marcia could be identified while possible melt deposits in Rheasilvia basin and Cornelia crater are still debated (Denevi et al., 2012; Williams et al., 2013). However, the small mass of Vesta and its location at a solar distance of $2.3 \mathrm{AU}$ are likely to result in a significantly greater percentage of low-velocity impacts than on the inner planets and the Moon, resulting in the preservation of major fractions of the projectile (O'Brien et al., 2011). Thus it is probable that dark material might have been introduced by impacts as remnants of impactor material (McCord et al., 2012). Dark material originating from carbonaceous chondrite-rich (CC) objects, especially from the outer parts of the asteroid belt and perhaps from comets, must have impacted Vesta's surface. Further, the spectrum of the dark material end member, as modeled by McCord et al. (2012), is similar to that of CC and organic-rich material in the outer Solar System. Exogenic infall is also supported by certain HED (howardites, eucrite, diogenite) meteorites, originating from Vesta (e.g. Russell et al., 2013), that contain clasts of carbonaceous chondrite material within a matrix of pyroxene-rich basaltic material (Cloutis et al., 2013; Herrin et al., 2011; McCoy and Reynolds, 2007). Moreover, the broad correlation between dark material and $\mathrm{OH}$ signature, detected by VIR, and $\mathrm{H}$ abundance, detected by GRanD, (De Sanctis et al., 2012b; Prettyman et al., 2012) is a further indication of carbonaceous chondrite as darkening agent of the Vestan regolith. Carbonaceous chondritic clasts are the main xenolithic clasts in howardites and exhibit varying degrees of aqueous alteration. These chondritic clasts can contain $\mathrm{H}_{2} \mathrm{O}$ in the form of hydrated, hydroxylated, or oxyhydroxylated mineral phases (Zolensky et al., 1996; Lorenz et al., 2007; Prettyman et al., 2012).

The major objective of this study is to investigate the subsurface layering of the dark material, their excavation and distribution process by impacts and, if the source is exogenic, whether it is due to multiple impacts or to only one or a few events.

\section{Data base and methods}

The Dawn mission orbited Vesta from July 16, 2011 until September 5, 2012, using three instruments to observe the surface (Russell and Raymond, 2011). The Visual and Infrared Spectrometer (VIR) detects surface mineralogical compositions by measuring spectral variations in the range from $\sim 0.4$ to $5.0 \mu \mathrm{m}$ and corresponding absorption features (De Sanctis et al., 2010). The Gamma Ray and Neutron Detector (GRaND) provides information on the elemental composition of the surface (Prettyman et al., 2011). The Dawn Framing Camera (FC) observes the surface in seven colors in the visible to near-infrared wavelength range. FC also provides stereo coverage by systematically changing observation geometries (Sierks et al., 2011; Raymond et al., 2011). Calibrated Dawn Framing Camera data (Schröder et al., 2013a) as well as the digital terrain model (DTM) obtained during the Dawn High Altitude Mapping Orbits (HAMO 1 and 2) (Jaumann et al., 2012a; Preusker et al., 2012) were used in our geological analysis of the dark material on Vesta. During the orbital phases, the FC mapped the surface at image scales of $\sim 260 \mathrm{~m} /$ pixel (FC) in the survey phase, $\sim 60 \mathrm{~m} /$ pixel in HAMO and $\sim 20 \mathrm{~m} /$ pixel in the Low Altitude Mapping Orbit (LAMO). The stereo-photogrammetric processing of Dawn images is based on a software suite that has been applied successfully to several planetary stereo image data sets (Jaumann et al., 2007; Gwinner et al., 2009; Preusker et al., 2011). There are five steps to gain Dawn stereo-photogrammetry: photogrammetric block adjustment; multi-image matching; surface point triangulation; digital terrain model (DTM) generation; and base map generation (Raymond et al., 2011). Elevations refer to a best approximation of Vesta's irregular shape - a biaxial ellipsoid with a semi-major axis of $285 \mathrm{~km}$ and a semi-minor axis of $229 \mathrm{~km}$. The resulting DTM covers $\sim 90 \%$ of Vesta's surface and has a grid spacing of 48 pixels per degree ( $\sim 92 \mathrm{~m} /$ pixel, with a vertical resolution of $<10 \mathrm{~m}$ ) (Jaumann et al., 2012a; Preusker et al., 2012). Based on the DTM, a global HAMO (60 m/pixel spatial resolution) and a LAMO (20 m/pixel spatial resolution) mosaic were derived (Roatsch et al., 2012). To correct for brightness changes due to local topography within the image and brightness changes due to differences in phase angle between images, we used a photometric adjustment based on the disk function for the former and a phase function for the latter (Li et al., 2013; Schröder et al., 2013b). Schröder et al. (2013b) used an approach based on models in which the explicit dependence of reflectance on phase angle is decoupled from the effects of local topography (Kaasalainen et al., 2001; Shkuratov et al., 2011). Their approach separates the disk function from the phase function, and is well suited to facilitate photometric correction by combining the best-fit disk function of Vesta with a polynomial to describe the phase function. Radiometric and photometric correction has been applied to the entire HAMO and 
LAMO mosaics (Schröder et al., 2013a, 2013b). This permits distinguishing between dark material and shadows by comparing albedo images, DTMs and photometrically corrected images.

At a resolution of $20 \mathrm{~m} /$ pixel, features smaller than $\sim 100 \mathrm{~m}$ can be clearly identified. Each dark material deposits all over Vesta was (1) mapped in a GIS environment, (2) the albedo is calculated, (3) the local areal distribution and extent is estimated, (4) the geological context is classified, and (5) a catalog of all dark material deposits on is generated. For mapping and analyzing the geological settings of dark material we used the geographic information system ArcGIS developed by Environmental System Research Institute's (ESRI).

GIS-based mapping, i.e., the delineation of particular objects, uses the global LAMO mosaic ( $\sim 20 \mathrm{~m} /$ pixel) (Roatsch et al., 2012). This mosaic is based on the 'Claudia' coordinate system (Jaumann et al., 2012a, 2012b; Russell et al., 2012), which is different from the coordinate system used by the Planetary Data System (Li, 2013) that follows IAU recommendations (Archinal et al., 2011). Positive longitudes given in this paper are offset by $150^{\circ}$ from the 'IAU/PDS' system, in the sense that Claudia longitude = IAU longitude $-150^{\circ}$. The Dawn Science Team established the Claudia coordinate system following standard practices recommended by the IAU after improved rotation parameters for Vesta were identified. All Dawn team publications use the Claudia coordinate system, and to be consistent we continue to report all results in this system (e.g. survey orbit based geological map (Jaumann et al., 2012a) and the HAMO-based global map (Yingst et al., in press) use single, Claudia-based coordinates rather than double coordinates. We prefer that this paper remains consistent with all previous publications of the Dawn mission (Williams et al., 2014).

The first mapping step is to geometrically identify areas, regions or objects that are clearly darker than the immediate surroundings. With the help of DTMs, shadows are excluded. In the second mapping step, the boundary of every individual dark object is checked and - if necessary - modified on the basis of the photometrically corrected HAMO/LAMO mosaic (Li et al., 2013; Schröder et al., 2013b), which displays the albedo of Vesta. Albedo is expressed as the ratio of the reflected light measured in the photometrically corrected clear filter images and the incident solar radiation of the same wavelength range. Based on the geometrical identification of dark objects, their areal distribution and extent can be visualized and classified. Dark objects are distinguished by (a) the location where the dark material occurs, (b) the albedo values relative to the surroundings and (c) absolute compared to Vesta's average albedo. The albedo of dark surface materials of Vesta is estimated based on the albedo of photometrically corrected images using a set of pixels from a mapped dark albedo feature and its vicinity. The average albedo of Vesta's surface as estimated from the global HAMO mosaic is $0.32 \pm 0.04$, making Vesta a relatively bright object compared to other asteroids and the Earth's Moon. In order to characterize a deposit as dark material the following parameters are used: (1) the albedo of the feature, (2) the albedo of the feature compared with the average albedo (da-ratio) of Vesta, (3) albedo boundaries that can be identified and mapped over a significant pixel distance and (4) albedo mixing ratios of the dark deposit and the material in the vicinity of this deposit (dv-ratio) in order to determine the local albedo heterogeneity. Material exposed on the surface is classified as dark where its albedo is (1) less than the average albedo and (2) lesser than the surrounding material clearly offset by a traceable unit boundary. Based on this definition, three major dark geological settings have been identified (Jaumann et al., 2012b; McCord et al., 2012): (1) material cropping out at crater walls, scarps and escarpments (dv-ratio 0.7-0.8, da-ratio 0.7-0.9); (2) material on crater rims in ejecta or mass wasting deposits (dv-ratio 0.5-0.8, da-ratio 0.4-0.7), and (3) dark regolith and linear dark features (dv-ratio $\sim 0.9$, da-ratio $\sim 0.8$ ).
Impact craters are used to constrain the subsurface position of dark material deposits. Where dark material crops out from crater walls or appears as dark ejecta we used the DTM to determine the depth of dark material deposits or layers. We were also able to determine the position of the dark material deposits by estimating the position of the outcrop below the crater rim or the crater depth. However, for craters smaller than the DTM horizontal resolution depths can only be estimated by the crater depth to crater diameter ratio. The depth $d$ of craters with diameters $D$ smaller than the DTM resolution can be derived from general crater depth/diameter ratio $(d / D)$ of 0.2 for simple craters as determined by Melosh (1989). In order to adapt this ratio to Vesta and constrain the possible depth error, first estimates from Vincent et al. (2012a) are applied to small craters (up to $30 \mathrm{~km}$ in diameter), covering a range of $d / D$ from 0.05 to 0.4 , with the larger ones clustering at a narrow peak centered on the mean value of $0.18 \pm 0.10$. This is consistent with crater depth/diameter ratios for Asteroid (21) Lutetia, which vary between 0.05 and 0.35 (Vincent et al., 2012b). For smaller fresh craters $(<5 \mathrm{~km})$ we used mean values ranging between 0.18 and 0.40, i.e., $0.3 \pm 0.1$ (Jaumann et al., 2012a; Vincent et al., 2012a, 2012b; Melosh, 1989). Based on the $d / D$-method we can constrain the depth of dark material deposits by estimating the pixel position of outcrops in crater walls in high resolution LAMO data as well as by measuring the depth of small impact craters that excavated dark material. However considering the transient cavity of small craters which is for simple crater types approximately 20-30\% deeper than the apparent crater depth (Croft, 1981; Melosh, 1989; Osinski and Pierazzo, 2013), the maximum excavation depth of dark material can be higher.

\section{Dark material deposits}

Deposits of dark material on Vesta are characterized by relatively low-albedo features partially excavated by younger impacts, exposed as individual layered outcrops in crater walls or as ejecta patches. Fig. 1 shows the nomenclature, true color overview and topographic map with the location of each individual figure indicated.

\subsection{Geological settings of dark material}

Dark material outcrops occur at different levels in crater walls and escarpments. The most prominent outcrops occurs in the western crater rim of Marcia (diameter $58 \mathrm{~km}$ ) at $184^{\circ} \mathrm{E}$ and $4-7^{\circ} \mathrm{N}$ (Figs. 1 and 2). This exposure is dominated by material moving down slope from a dark layer in the crater wall into the crater over a distance of about $20 \mathrm{~km}$ (Fig. 2). The dark material has accumulated on a plateau above the crater floor, covering about $225 \mathrm{~km}^{2}$. The albedo of the inner crater plateau is reduced by $32 \%$ compared to the immediate surroundings, indicating a net accumulation of dark material. The material seems to emanate from two different levels beneath the crater rim. The broadest continuous outcrop appears along a distance of $2.5 \mathrm{~km}$ between $4^{\circ}$ and $5^{\circ} \mathrm{N}$ at about $300-400 \mathrm{~m}$ beneath the rim. Farther north, between $5.2^{\circ}$ and $5.6^{\circ}$, individual outcrops also indicate the presence of dark material in the subsurface. At about $6.7-7.1^{\circ} \mathrm{N}$, another continuous outcrop extends over a distance of $\sim 1.3 \mathrm{~km}$ at a depth of $\sim 550 \mathrm{~m}$ beneath the rim. In between the two continuous outcrops, dark material is emanating from the crater wall at two areas $1 \mathrm{~km}$ and about $400 \mathrm{~m}$ wide. However, these outcrops appear 1000-1100 m beneath the rim. A smaller dark spot in between at the same topographic level indicates that these outcrops may be connected. The upper rim of Marcia is dominated by spur and gully structures (Figs. 2 and 3) in which the competent spur ramps are composed of bright material. From the top level, above the dark horizons, less 

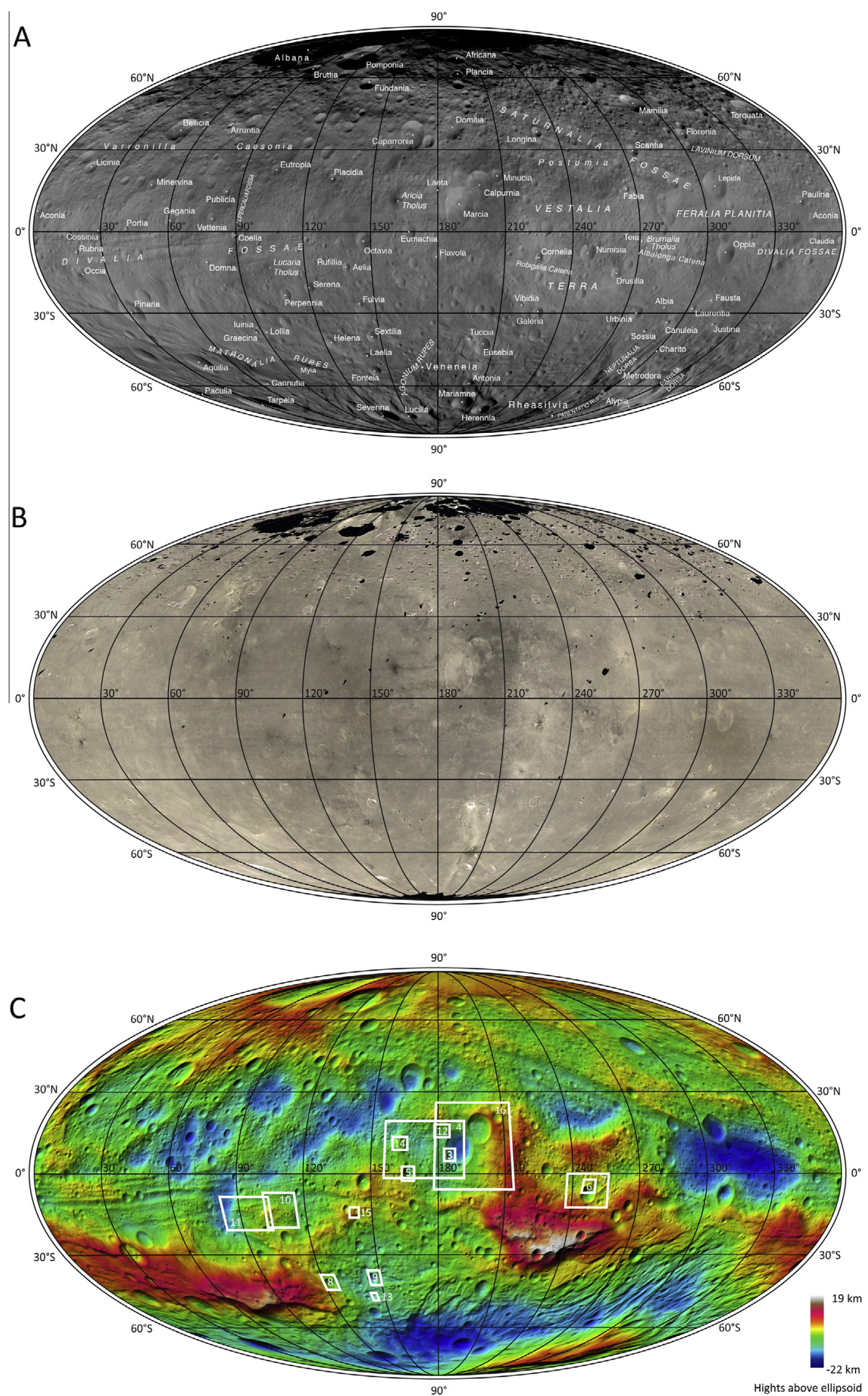

Fig. 1. Global overviews of Vesta in Mollweide projection. (A) Mosaic of the clear filter albedo with the nomenclature of surface features indicated. (B) True color mosaic (filter red $650 \mathrm{~nm}$, green $550 \mathrm{~nm}$, blue $430 \mathrm{~nm}$ ) enhancing the global distribution of dark material as brightness reduction in all filters. (C) Digital terrain model with the position of the following figures indicated as numbered boxes (Jaumann et al., 2012a; Roatsch et al., 2012). (For interpretation of the references to color in this figure legend, the reader is referred to the web version of this article.) 

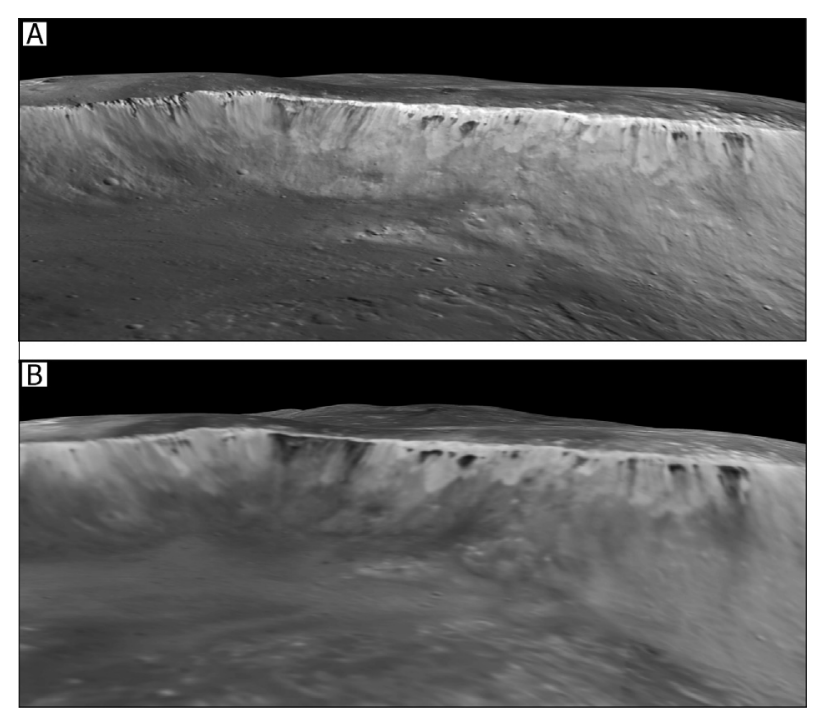

Fig. 2. Perspective view of dark material cropping out on the western crater rim of Marcia $\left(184^{\circ} \mathrm{E}, 4-7^{\circ} \mathrm{N}\right)$. The material originates at two different horizons a few hundred meters beneath the rim over a distance of $20 \mathrm{~km}$. Dark material cropping out has albedo approximately $32 \%$ lower than the surrounding area. (Data base: (A) LAMO mosaic (resolution $20 \mathrm{~m} /$ pixel); (B) HAMO photometric corrected (resolution $60 \mathrm{~m} /$ pixel).)

competent bright material is found between the spurs and forms avalanche-like deposits that end in lobate aprons. These bright avalanches overlay the dark material, which originates beneath the bright horizon of the upper rim. Besides the dark outcrops in the western rim of Marcia, only a few spots occur in the close-by southern rim area at about $4.2-4.9^{\circ} \mathrm{N}$ and farther north at about $13.8^{\circ} \mathrm{N}$, and one dark avalanche in the eastern rim of the adjacent Calpurnia crater at $208^{\circ} \mathrm{E}, 20^{\circ} \mathrm{N}$ (Fig. 1). Because Marcia covers a large area, the concentration of the dark material in a relatively small part of its western wall indicates a limited spatial extension of the dark subsurface layer.

A $20 \mathrm{~km}$ broad area with a significantly reduced surface albedo extends $100 \mathrm{~km}$ from the Marcia dark outcrops to the west (Fig. 4). It is plausible to assume that in this area material from the dark layer was mixed into the Marcia ejecta. The correlation of this dark surface area with the outcrops in the western wall of Marcia, dark spots in the walls of some larger craters in this area, and dark ejecta of small impact craters indicate a relatively large subsurface layer of dark material covering about $2000 \mathrm{~km}^{2}$.
A few smaller craters ( $\sim 1 \mathrm{~km}$ diameter) west of the Marcia crater rim show dark ejecta (Fig. 4). An unnamed crater at $175.5^{\circ} \mathrm{E}$ and $4.5^{\circ} \mathrm{N}$ and Eumachia $\left(167.1^{\circ} \mathrm{E}\right.$ and $0.1^{\circ} \mathrm{S}$ ) (Figs. 4 and 5) exhibit a few patches of dark material exposed in the crater wall and rim. Other examples of outcrops of dark material are found in larger craters with diameters between 15 and $32 \mathrm{~km}$ to the east and west of Marcia. The majority of these craters are located north of $21^{\circ} \mathrm{S}$. One example is the Numisia crater at $247^{\circ} \mathrm{E}$ and $7^{\circ} \mathrm{S}$, which exhibits outcrops in its northern wall (Fig. 6). The outcrops are correlated with competent bright spur cliffs located about $2000 \mathrm{~m}$ beneath the rim. In Numisia, dark material is exposed in the wall and subject to downslope mass wasting. However, in the northernmost and northeastern part of the crater, dark material also covers the part between the rim and the bright spur cliffs. Smaller craters with diameters $<300 \mathrm{~m}$ in the vicinity of these dark upper wall parts show dark ejecta, indicating the presence of dark material in the upper subsurface. An area north and northwest of Numisia covering about $2150 \mathrm{~km}^{2}$ (Fig. 7) exhibits a lower albedo than the surroundings (dv-ratio $\sim 0.9$ da-ratio $\sim 0.8$ ), indicating dark material was mixed into the regolith by preexisting impacts. The crater walls of Numisia extending to the south do not show any outcrops. Therefore the dark subsurface layer appears to be restricted to the low-albedo area north of the crater. However, a few small craters of about $1 \mathrm{~km}$ in size with dark features appear in the western and southern ejecta of Numisia. One of these small impacts appears exactly on the southern crater rim (Fig. 7), while another is located about $6 \mathrm{~km}$ south of the rim. Both craters exhibit dark material mainly ejected as rays to the northeast and east.

Helena, an impact crater $22 \mathrm{~km}$ in diameter, is located at $122.5^{\circ} \mathrm{E}$ and $41.4^{\circ} \mathrm{S}$ (Fig. 8). Helena is one of the common asymmetric craters found on Vesta (Krohn et al., 2014). These craters form when impacts hit a steep slope. The ejecta debris is thrown out almost vertically and falls back into the downslope part of the crater, superimposing the downslope rim. The resulting morphological feature is a sharp crater rim on the upslope side, and a subdued, ejecta-covered rim downslope. The northwestern sharp rim of Helena shows several weak dark features that originate at $\sim 1 \mathrm{~km}$ beneath the upslope crater rim and extending over a distance of $\sim 3.5 \mathrm{~km}$. In addition, dark material directly emanating from small impacts on the crater rim indicates an intermixing of dark material with the ejecta of Helena in this area.

A number of other craters in the vicinity of Helena exhibit similar features, again resulting in a set of dark patches imbedded in the ejecta debris of these impacts (Fig. 8). Larger impacts such as Laelia $\left(140.5^{\circ} \mathrm{E}, 46.8^{\circ} \mathrm{S}\right)$ to the southeast of Helena, an unnamed crater east of Helena at $122.5^{\circ} \mathrm{E}, 41.4^{\circ} \mathrm{S}$, and, even farther north,
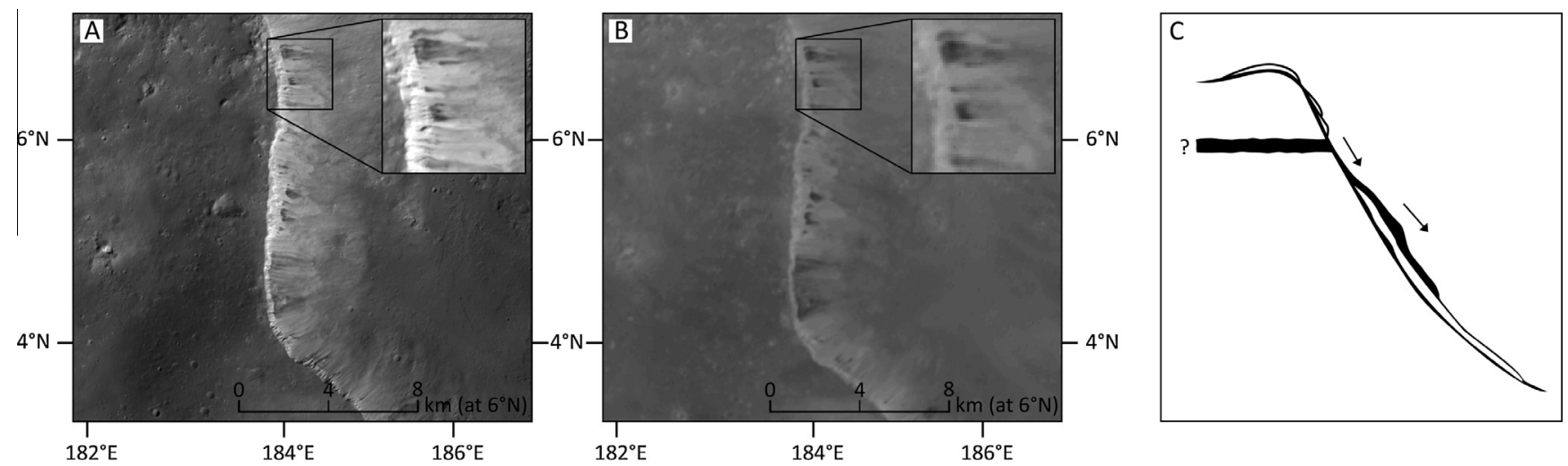

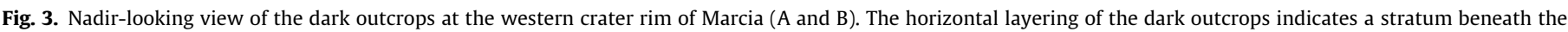

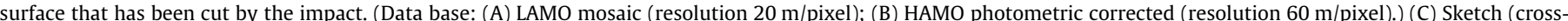

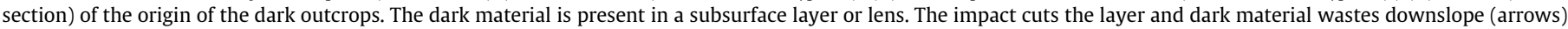
forming lobate aprons (? indicates the uncertain horizontal extent of the dark layer). 


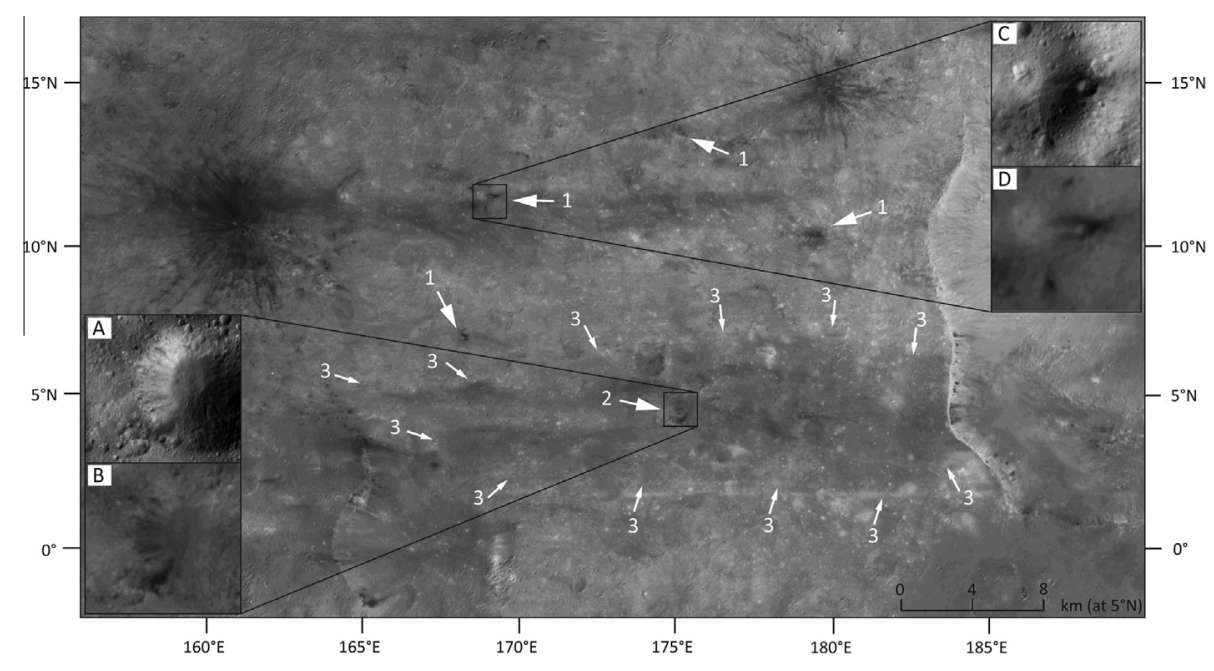

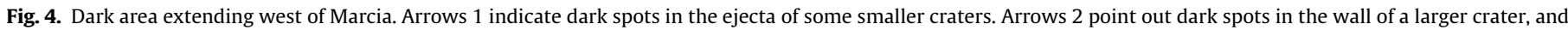

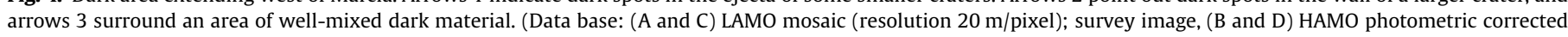
(resolution $60 \mathrm{~m} / \mathrm{pixel})$.)
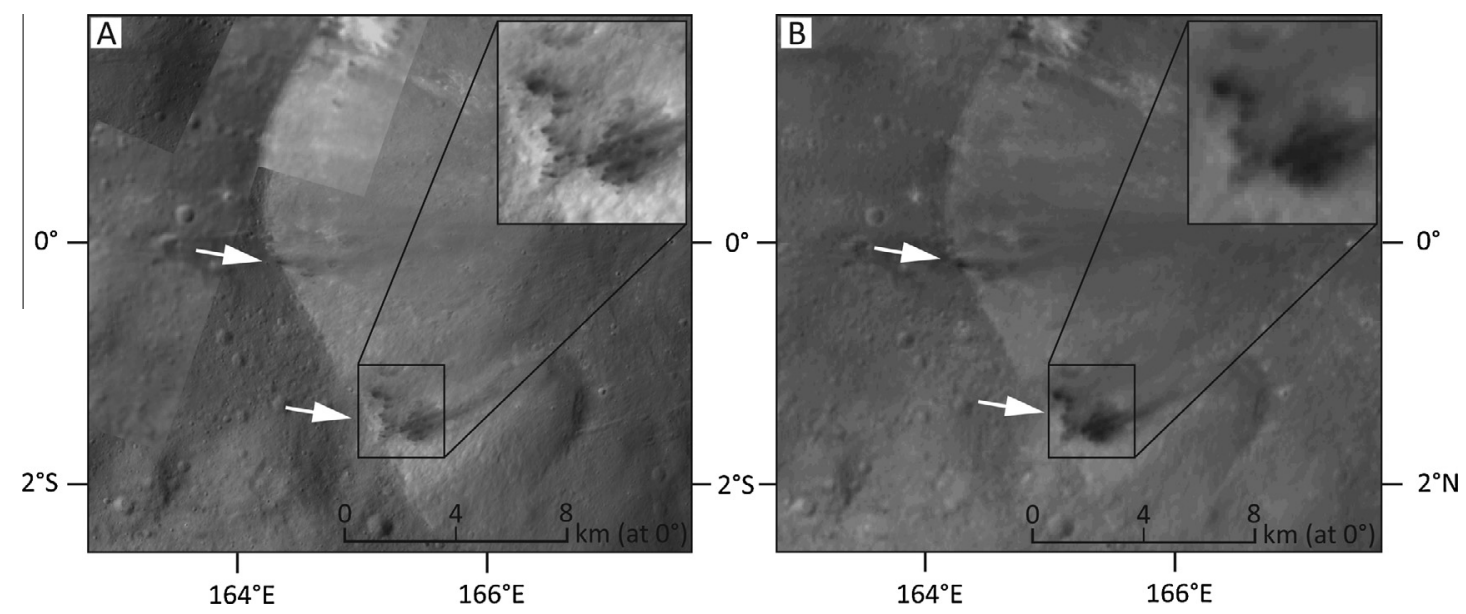

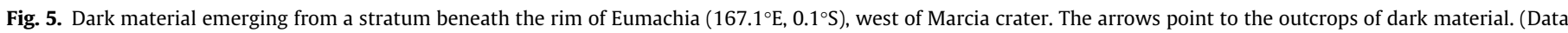
base: (A) LAMO mosaic (resolution $20 \mathrm{~m} /$ pixel) complemented with HAMO mosaic (resolution 70 m/pixel); (B) HAMO photometric corrected (resolution 60 m/pixel).)

Serena $\left(120.7^{\circ} \mathrm{E}, 20.5^{\circ} \mathrm{S}\right)$, Aelia, $\left(140.7^{\circ} \mathrm{E}, 14.2^{\circ} \mathrm{S}\right)$ and Octavia $\left(147^{\circ} \mathrm{E}, 3.3^{\circ} \mathrm{S}\right.$ ) (Fig. 1) show dark outcrops in their crater walls at distances of $<1000 \mathrm{~m}$ beneath their rims. This indicates that the whole area in between these craters contains larger amounts of dark material in the subsurface. The largest crater in this area, Sextilia $\left(144^{\circ} \mathrm{E}, 3^{\circ} \mathrm{S}\right)$ (Fig. 9), has dark material cropping out in a small spot on its northwestern wall close to the rim. A similar small outcrop occurs on the opposite crater wall in the southeast. On its northwestern side, a set of five craters exactly aligned at $45^{\circ}$ to the northern direction from the spot in the crater wall show dark ejecta. The sizes of these craters ranges from about $500 \mathrm{~m}$ to $800 \mathrm{~m}$, indicating an area of dimensions $\sim 25 \mathrm{~km}$ long and $2 \mathrm{~km}$ wide where dark material is present at a depth of $\sim 100-320 \mathrm{~m}$ assuming a crater diameter-to-depth ratio of $0.3 \pm 0.1$. Considering the transient cavity the maximum depth can be about $20-30 \%$ deeper.

Some areas on Vesta lack large craters with dark outcrops but show fields of dark patches which are mostly due to excavation of dark material by small impacts $<2 \mathrm{~km}$ crater diameter (Fig. 10). Individual dark ejecta craters of $200-500 \mathrm{~m}$ in diameter, distributed over an area extending $50 \mathrm{~km}$ from east to west and $15 \mathrm{~km}$ from north to south indicate the presence of dark material at $\sim 50-200 \mathrm{~m}$ beneath the surface. Similar dark areas are found at several places on Vesta, with most of them clustering between $100^{\circ}$ and $155^{\circ} \mathrm{E}$. Other elongated dark features about $3-6 \mathrm{~km}$ wide and up to $100 \mathrm{~km}$ long appear along the equator between $14^{\circ}$ and $18^{\circ} \mathrm{S}$ (Fig. 11). These also seem to originate from ejecta of small craters excavating dark material while others in the immediate vicinity do not. A possible reason for this observation might be that locally distributed dark material in the subsurface has accumulated in elongated depressions.

\subsection{Interpretation of craters with dark material outcrops}

The dark material outcrops originating from the base of spur ramps and also avalanching downslope indicate strata of bright more competent material overlying dark, less competent material. The dark material does not reach the downslope extent of the bright avalanches showing the amount of dark material to be limited with respect to the bright material. This constrains the thickness of the dark layer in the crater walls to less than the bright overlying layer. Dark outcrops are best resolved in the western part of the Marcia crater rim covering 2-4 pixels translating to less than $100 \mathrm{~m}$ (Figs. 2 and 3). The dark strata cropping out at about the 

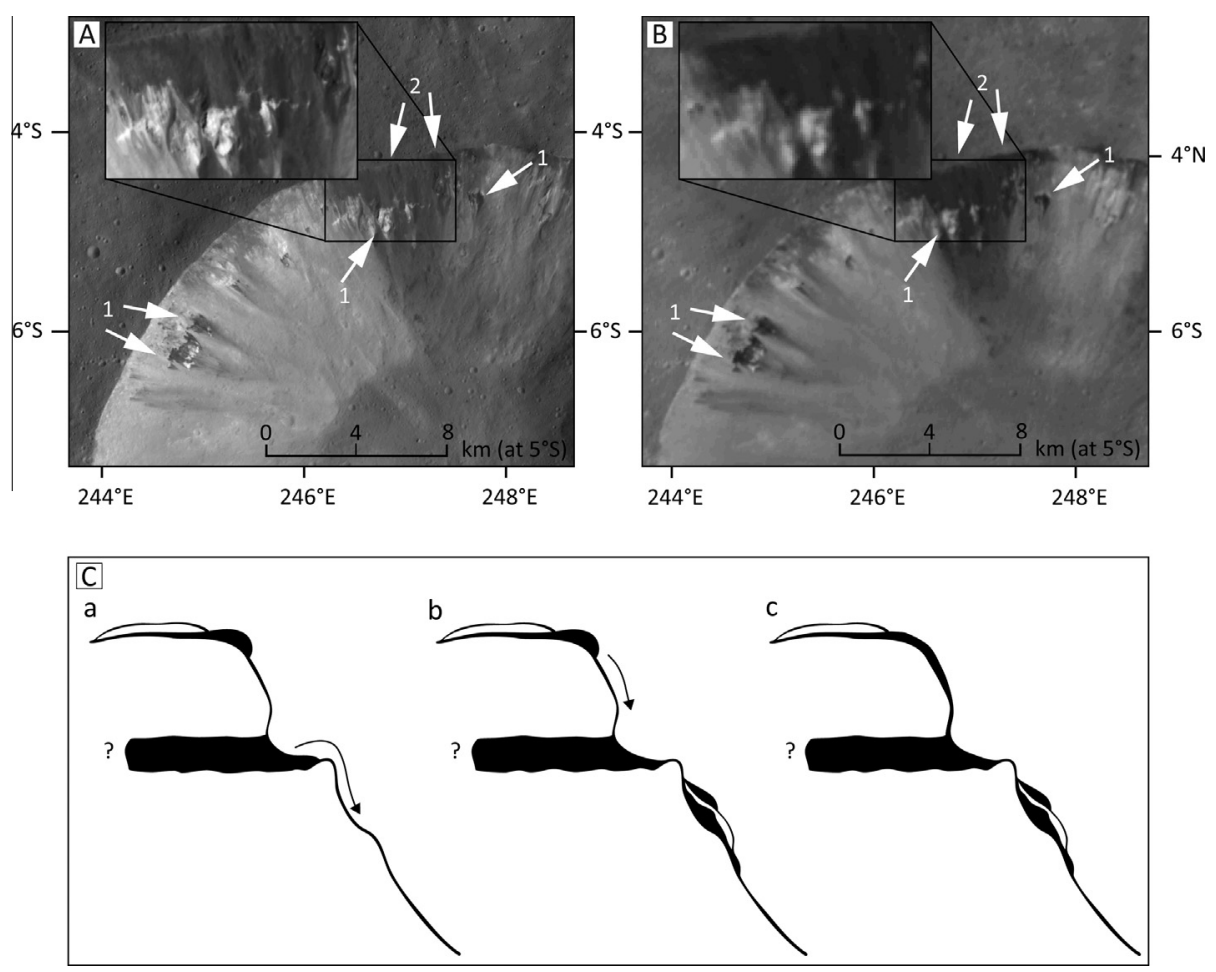

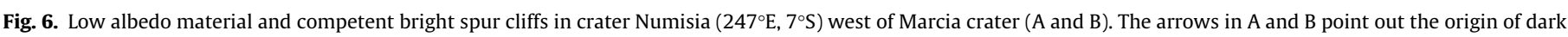

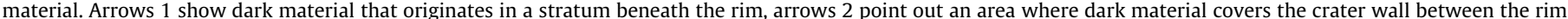

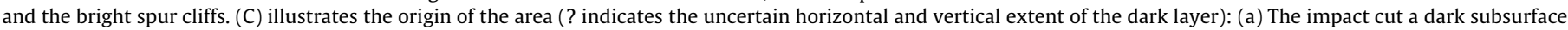

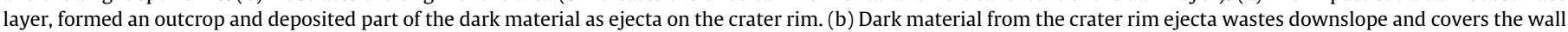

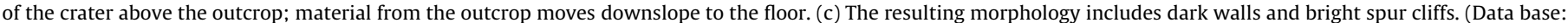
(A) LAMO mosaic (resolution $20 \mathrm{~m} /$ pixel); (B) HAMO photometric corrected (resolution $60 \mathrm{~m} / \mathrm{pixel}$ ).)

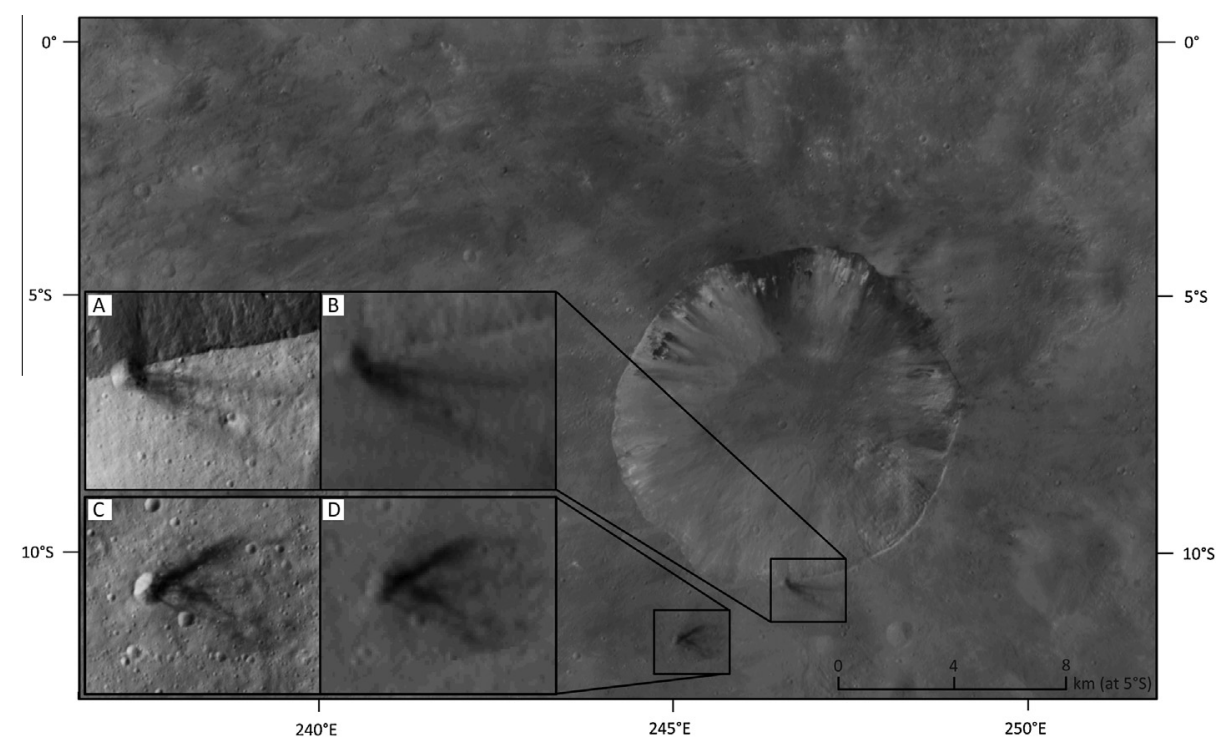

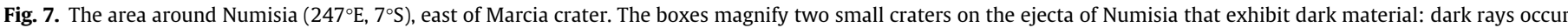

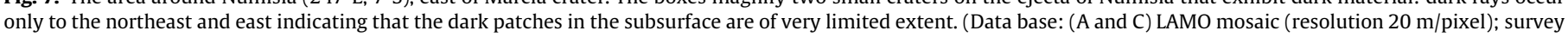
image, (B and C) HAMO photometric corrected (resolution $60 \mathrm{~m} / \mathrm{pixel}$ ).)

same topographic height in the crater wall implies it is approximately a horizontal layer beneath the surface that has been penetrated by the impact. The dark layer is superimposed by bright material of a few hundred meters to $\sim 1 \mathrm{~km}$ thickness. The fact that the outcrops occur only at the western rim of Marcia crater and that they are discontinuous suggests that the dark material in the subsurface occurs in isolated patches rather than continuously extended layers. However, if the outcrops of dark material are part of a continuous subsurface layer, traces of dark material should be visible on the surface west of crater Marcia, at least in the ejecta of craters that have penetrated to the depth of that layer. Assuming a depth-to-diameter ratio for small bowl-shaped craters of $0.3 \pm 0.1$ (Jaumann et al., 2012a; Vincent et al., 2012a, 2012b; Melosh, 1989), impacts producing craters of the size of $700 \mathrm{~m}$ to $4 \mathrm{~km}$ in 

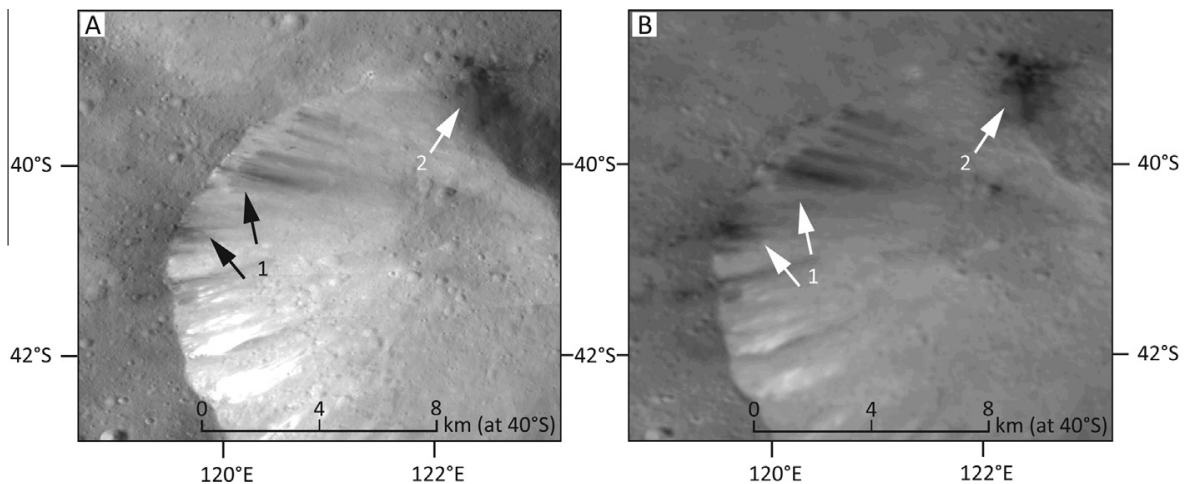

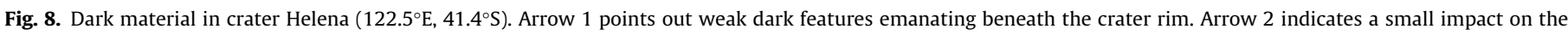
crater rim. (Data base: (A) LAMO mosaic (resolution 20 m/pixel); (B) HAMO photometric corrected (resolution $60 \mathrm{~m} /$ pixel).)
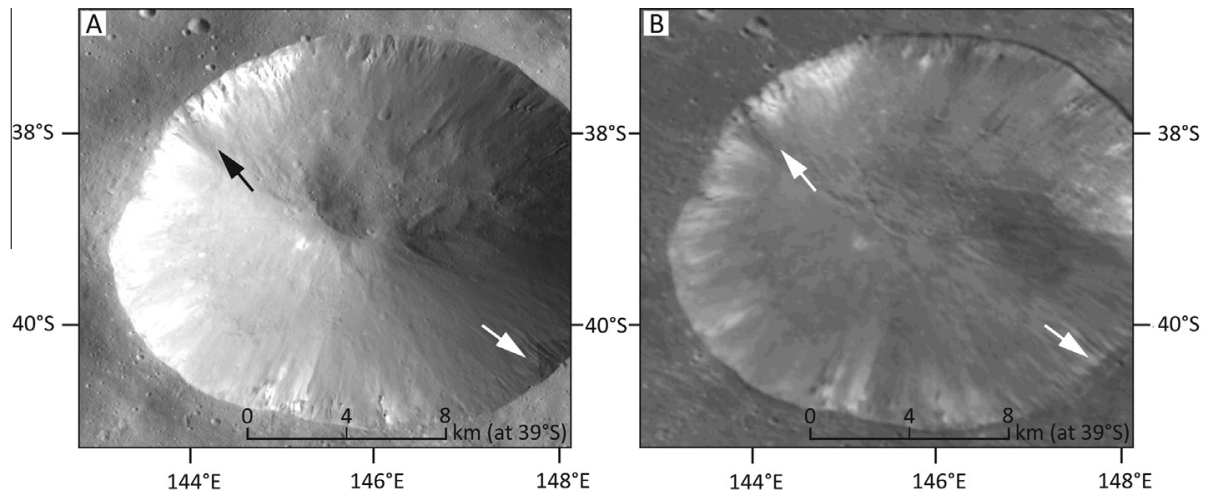

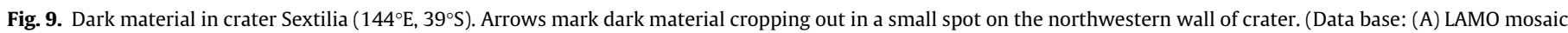
(resolution $20 \mathrm{~m} /$ pixel); (B) HAMO photometric corrected (resolution $60 \mathrm{~m} /$ pixel).)
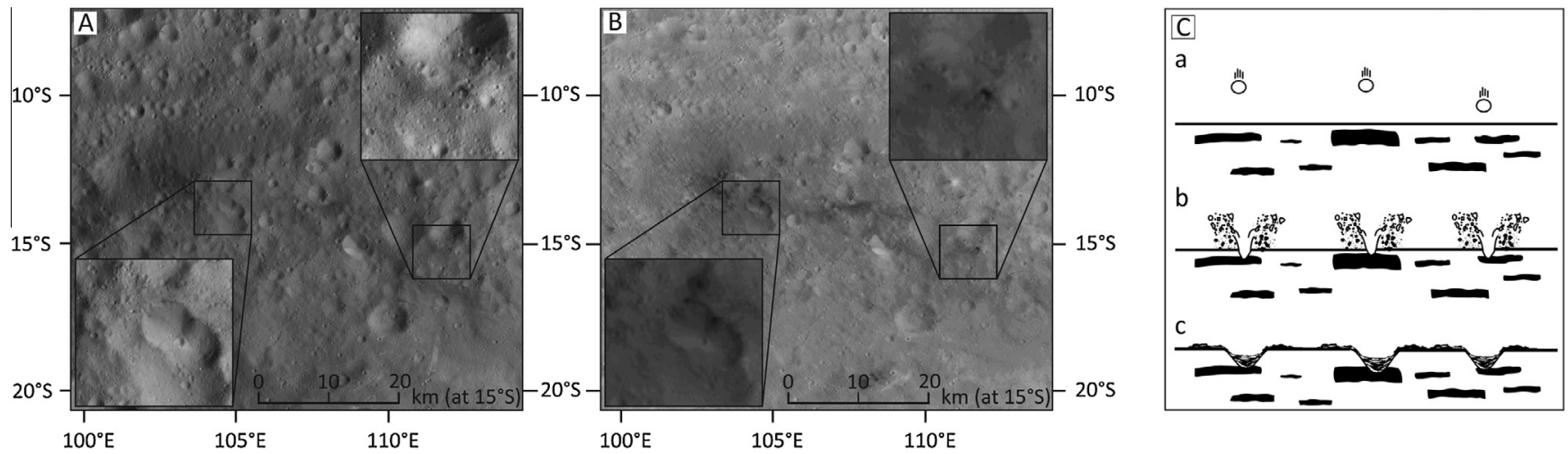

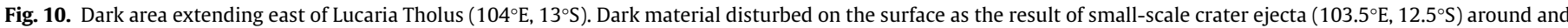

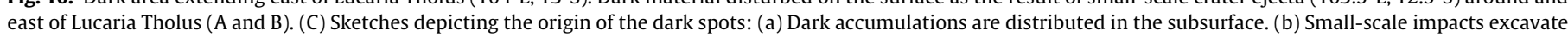

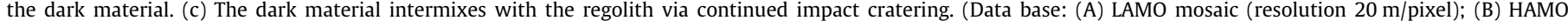
photometric corrected (resolution $60 \mathrm{~m} /$ pixel).)

diameter should reach the dark layer at depths of 200-1000 $\mathrm{m}$ and distribute dark material onto the surface. Considering the transient cavity the maximum depth can be about $20-30 \%$ deeper. An unnamed crater at $175.5^{\circ} \mathrm{E}$ and $4.5^{\circ} \mathrm{N}$ and Eumachia $\left(167.1^{\circ} \mathrm{E}\right.$ and $0.1^{\circ} \mathrm{S}$ ) (Figs. 4 and 5) exhibit a few patches of dark material exposed in the crater wall and rim, also at a depth of about $500-1000 \mathrm{~m}$ beneath the surface.

The concentration of dark material in the Numisia ejecta exactly at the part of the crater where dark material outcrops (Fig. 7) demonstrates that dark material was mixed within the ejecta, deposited close to the crater rim and subsequently wasted down the rim after the crater was formed. The dark material at the crater rim and in the nearby ejecta originates from the dark subsurface layer that is exposed in the northern crater wall. As other similar sized craters on the Numisia ejecta do not show dark features (Fig. 6), an extended dark layer beneath the Numisia ejecta is unlikely. Presumably, these dark deposits either result from the impactor itself, or dark material from the northern layer has been 


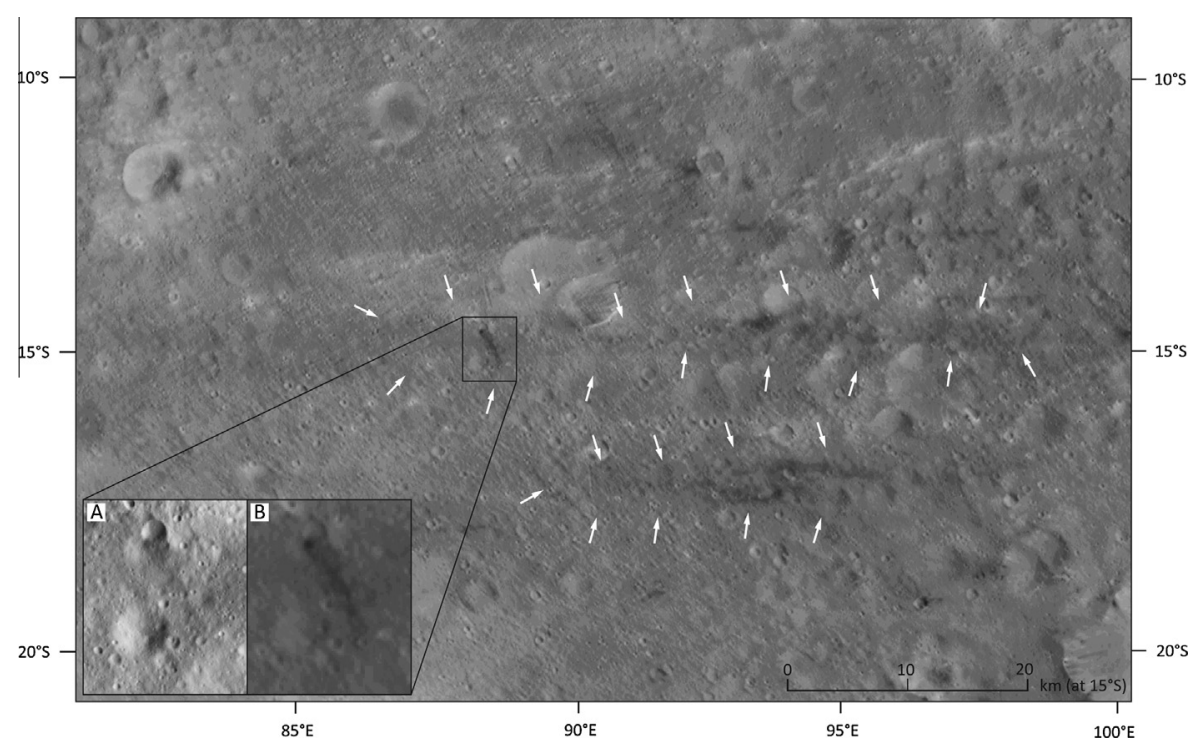

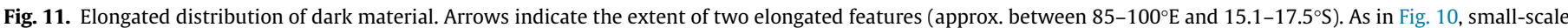

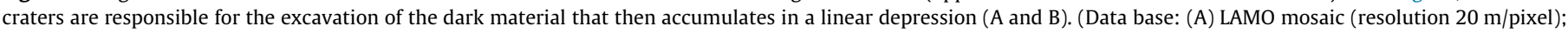
survey image and (B) HAMO photometric corrected (resolution $60 \mathrm{~m} / \mathrm{pixel}$ ).)

incorporated into the Numisia ejecta, and this dark debris has been further affected by subsequent smaller impacts.

As observed in various other craters, outcrops of dark material only occur in a restricted part of the crater wall. This is consistent with spatially restricted layers or patches of dark material in the subsurface that have been partially excavated by impacts. This inference is further substantiated by the presence of dark spots exposed in the fallback ejecta that cover the downslope rim. In the area of Helena (Fig. 8), dark material is randomly mixed into the ejecta debris and exposed again by more recent, smaller impacts. An example is the $1.5 \mathrm{~km}$ diameter crater on the fall back debris in the northern part of Helena (Fig. 8). This crater is located on the edge of the Helena ejecta debris covering the downslope rim, and exposes dark material mostly originating from this debris cover to the east. Other small craters $(<1 \mathrm{~km})$ on the ejecta debris sheet have also excavated dark material. This is an indication that dark material has been mixed into the Helena ejecta in discrete patches.

In the area southeast of crater Helena, smaller craters, $500 \mathrm{~m}$ to $1.5 \mathrm{~km}$ in diameter, have also clearly excavated dark material. This might be due to the fact that smaller impacts expose patches of dark material that had been mixed in the ejecta of the larger impacts. However, it cannot be ruled out that these smaller impacts have also tapped the original layer of dark material in the subsurface at depths of $\sim 100 \mathrm{~m}$ to a few hundred meters. The outcrops as well as the dark ejecta of the smaller craters imply that these layers are no more than 10-20 m thick. Most of the craters larger than about $2 \mathrm{~km}$ in this area do not show any distinct dark ejecta. A possible explanation is that craters slightly larger than $2 \mathrm{~km}$ have completely destroyed the thin layer and the amount of dark material mixed into the ejected material was too small to noticeably darken the ejecta. However, there are also craters larger than $10 \mathrm{~km}$ in this area that does not have any dark material in their walls and ejecta. These strongly suggest that at these locations no dark material is present in the subsurface and that the dark layers are locally restricted deposits rather than large regionally extended sheets.

\subsection{Interpretation of craters with dark ejecta}

A crater, named Laeta, with obvious dark ejecta (dv-ratio 0.7 and da-ratio 0.6 ) is located at $180^{\circ} \mathrm{E}$ and $14.9^{\circ} \mathrm{N}$ (Williams et al.,
2014, this issue), about $20 \mathrm{~km}$ northwest of the northernmost isolated dark spots in the Marcia western wall (Fig. 12). The crater has a diameter of $1400 \mathrm{~m}$, and its continuous ejecta blanket covers about $17.5 \mathrm{~km}^{2}$. The continuous ejecta blanket and even the discontinuous dark rays exhibit a well-defined boundary with respect to the surrounding regolith (Williams et al., 2014, this issue). Based on a crater depth-to-diameter ratio for fresh craters of $0.3 \pm 0.1$, the crater depth is between 280 and $560 \mathrm{~m}$. The dark ejecta blanket indicates that the impact has struck the subsurface dark layer at least at this depth. Considering the transient cavity the maximum depth can be about $700 \mathrm{~m}$.

Like this dark halo crater west of Marcia, other examples can be found where dark material has been excavated by small impacts on the ejecta sheet of a larger crater that also shows outcrops of dark material. Laelia $\left(140.5^{\circ} \mathrm{E}, 46.8^{\circ} \mathrm{S}\right.$, southeast of Helena) possesses a very prominent dark halo crater of $630 \mathrm{~m}$ diameter on its ejecta, exposing dark material from Laelia's ejecta about 130-320 m beneath the surface (Fig. 13). Small patches of dark material excavated by even smaller impacts on the Laelia ejecta indicate that dark material in the subsurface was exposed by the Laelia impact and mixed with its ejecta at different levels. In addition this dark halo crater constrains the thickness of the Laelia ejecta to a few hundred meters.

About $100 \mathrm{~km}$ to the west of the Marcia crater rim, there is a dark hill named Aricia Tholus $\left(161.8^{\circ} \mathrm{E}\right.$ and $12.1^{\circ} \mathrm{N}$ ) (Williams et al., 2014, this issue). Aricia Tholus is about $2000 \mathrm{~m}$ high. An impact crater with a diameter of $2.5 \mathrm{~km}$ is located on the top of the tholus (Figs. 4 and 14). This impact has excavated dark material, which is expressed as dark rays extending radially outward to about four crater radii. The formation of dark rays rather than continuous dark ejecta indicates an uneven distribution of the dark component in the ejecta. In some parts, the dark material appears to have accumulated in elongated depressions on the flanks of the hill, which might be a result of the finer-grained characteristics of the dark component compared with the rest of the ejected regolith.

Like the dark areas in the south, between Aricia Tholus $\left(161.8^{\circ} \mathrm{E}\right.$, $\left.12.1^{\circ} \mathrm{N}\right)$ and the dark halo crater Laeta $\left(180^{\circ} \mathrm{E}, 14.9^{\circ} \mathrm{N}\right)$ to the east, all impact craters $1-2 \mathrm{~km}$ in size show ejecta of reduced albedo (Fig. 14), indicating a dark layer at $\sim 200-1000 \mathrm{~m}$ depth based on an assumed crater depth-to-diameter ratio of $0.3 \pm 0.1$ and taking into account the transient cavity. Larger craters do not show this effect, so the dark layer must be thin, and can thus easily have been 

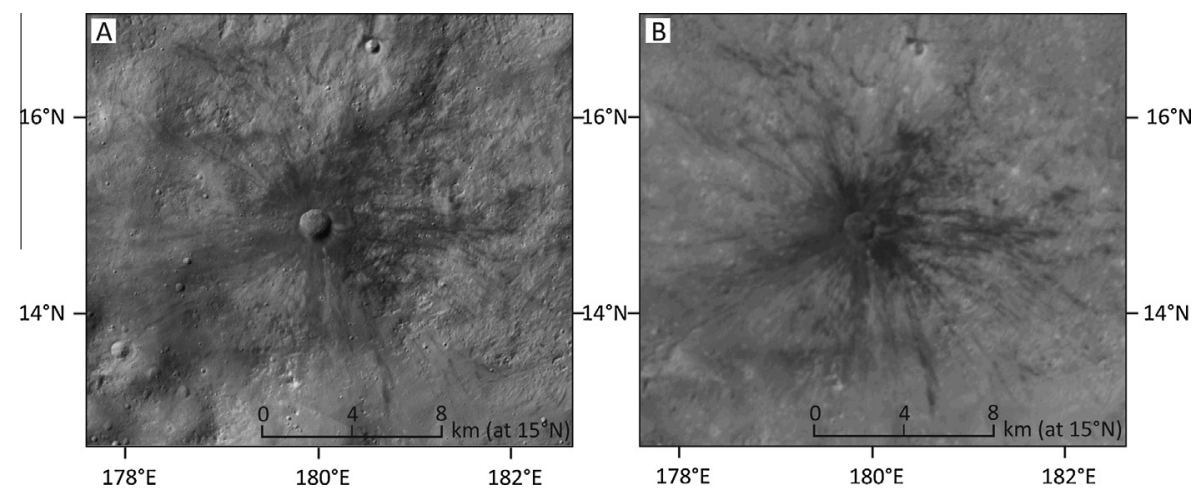

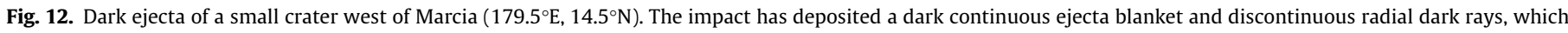
exhibit clear boundaries with the surrounding regolith. (Data base: (A) LAMO mosaic (resolution 20 m/pixel); (B) HAMO photometric corrected (resolution 60 m/pixel).)

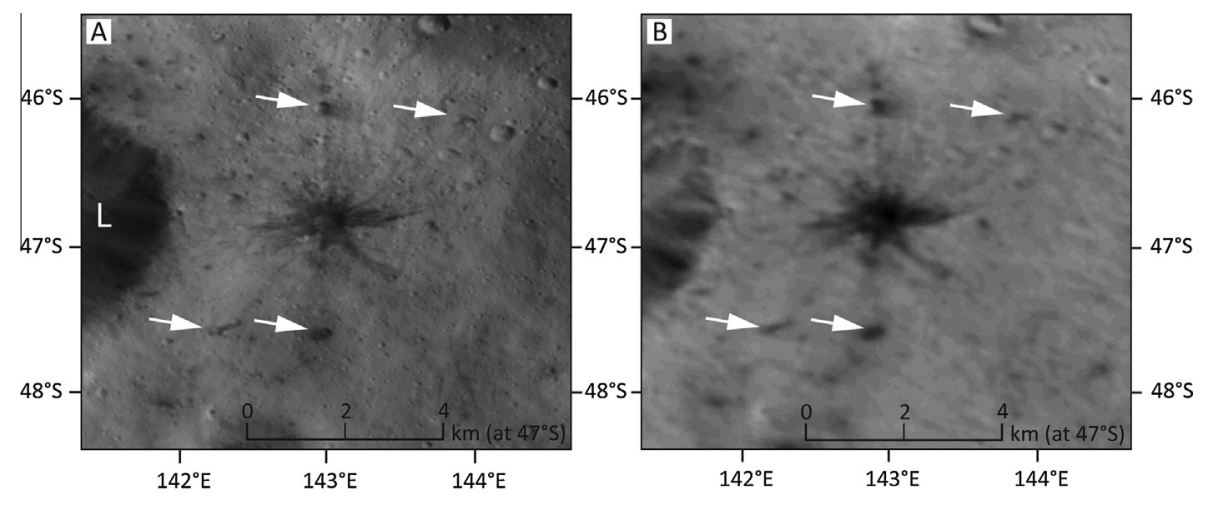

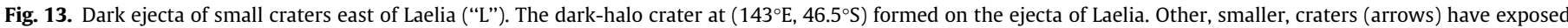

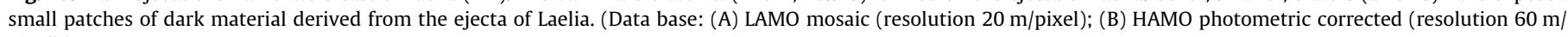
pixel).)

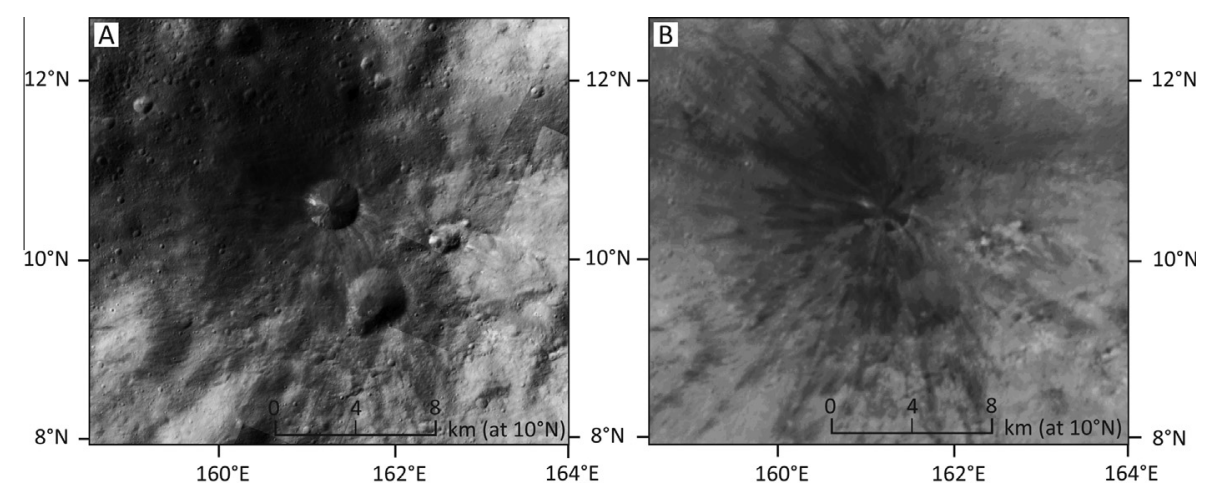

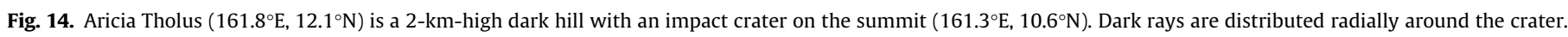
(Data base: (A) LAMO mosaic (resolution $20 \mathrm{~m} / \mathrm{pixel}$ ); (B) HAMO photometric corrected (resolution $60 \mathrm{~m} / \mathrm{pixel}$ ).)

destroyed and mixed with other ejected material by larger impacts.

Similar to the dark rays extending radially outward of Aricia Tholus, a $2.5 \mathrm{~km}$ Aelia impact crater at $\left(140.7^{\circ} \mathrm{E}, 14.2^{\circ} \mathrm{N}\right)$ (Fig. 15 ) shows dark material as a swirl-like striation emanating from the crater. This might suggest that the projectile was composed of dark material and the dark striations are the result of projectile material mixed into the ejecta. Survival of the impactor is plausible due to the low impact velocities at Vesta's position in the main asteroid belt (O’Brien et al., 2011; Reddy et al., 2012). However, cropping out of dark material in the crater wall, $\sim 200-300$ m below the crater rim at exactly such positions where the striations originate make an excavation from the subsurface more likely. In addition, the occurrences of the striations indicate an inhomogeneous distribution of the dark material in the subsurface as small patches rather than extended layers. This impact produced an asymmetric crater (Jaumann et al., 2012a; Krohn et al., 2014), striking a southto-north tilted slope with fallback ejecta covering the northern downslope rim. This explains the lack of dark outcrops and striations in the northern part of the crater (Fig. 15).

Small outcrops in the eastern wall of Marcia $\left(195^{\circ} \mathrm{E}, 8^{\circ} \mathrm{N}\right)$ just opposite to the western outcrops in this crater appear to be the source of dark material distributed close to the crater rim, probably as part of the ejecta (Fig. 16). Small patches of dark material are also found on the southern ejecta of Marcia. The area east of Marcia and Calpurnia between these impacts and the northern part of 


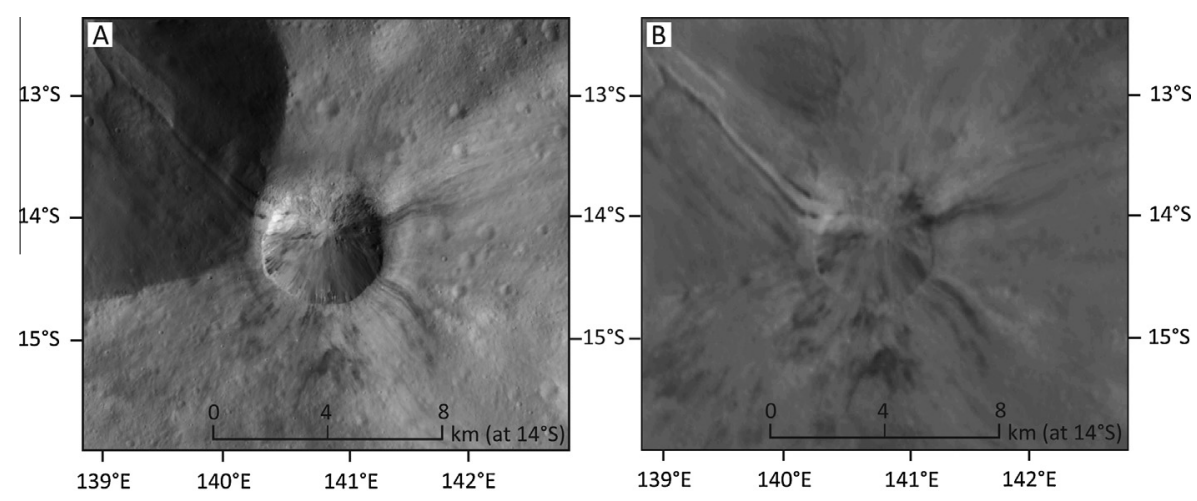

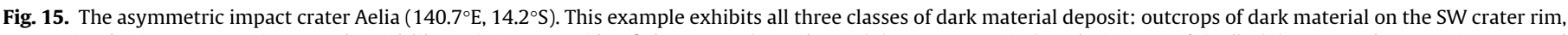

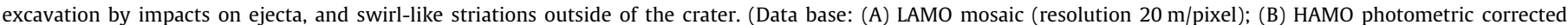
(resolution $60 \mathrm{~m} /$ pixel).)
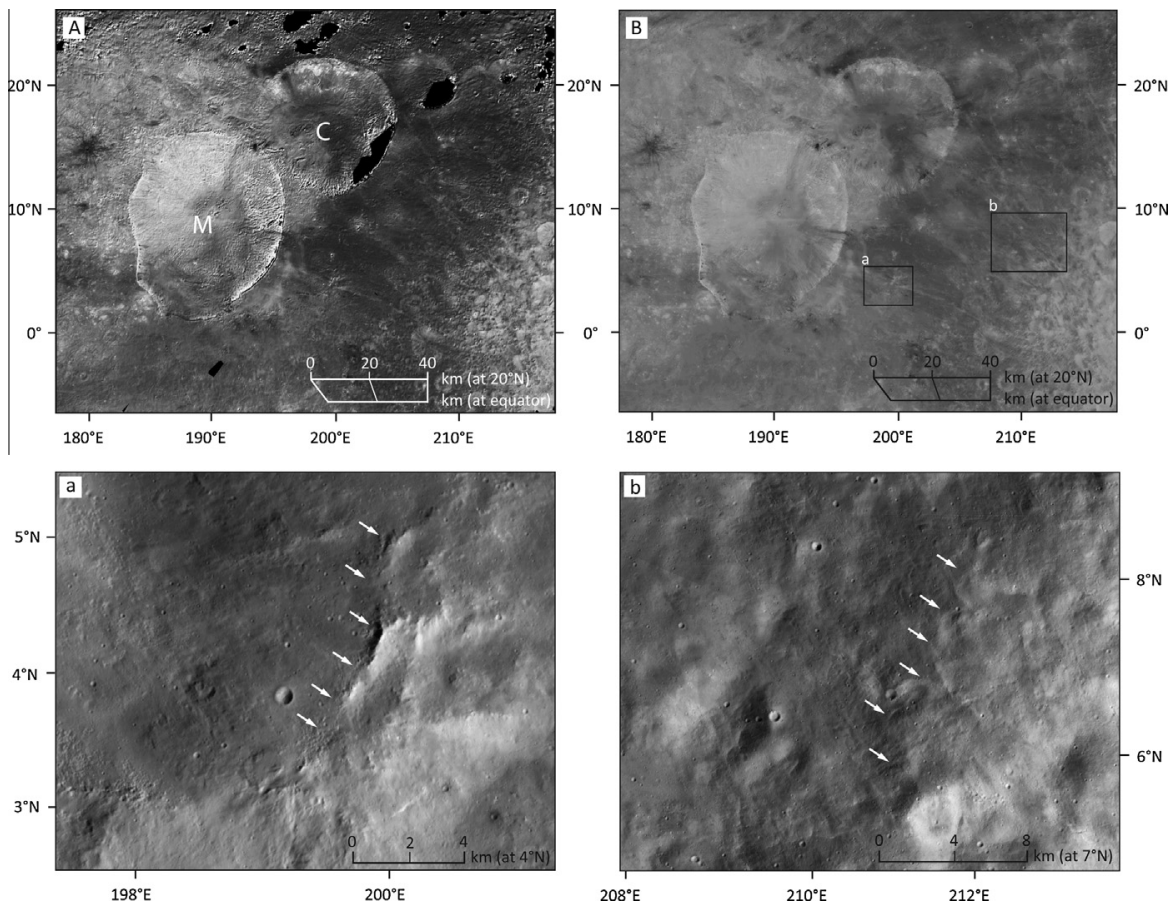

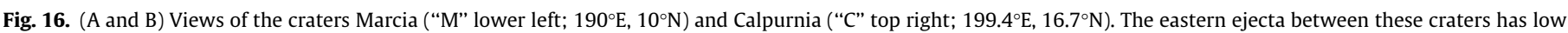

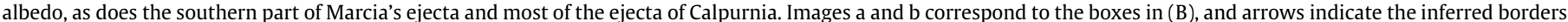

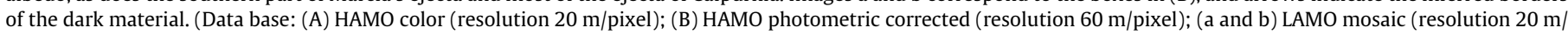
pixel).)

Vestalia Terra is also covered with dark material extending from $196^{\circ} \mathrm{E}$ to $218^{\circ} \mathrm{E}$ and $7^{\circ} \mathrm{S}$ to $18^{\circ} \mathrm{N}$ (Yingst et al., 2013; Williams et al., 2014) with a dv-ratio $\sim 0.7$ and a da-ratio $\sim 0.7$. However, the geological setting is different than in the western part of Marcia and appears diffuse. Here the dark material is tenuously covering the surface, thinning out to the east and accumulating against topographic obstacles at its eastern boundary (Fig. 16). Smaller and fresher impacts do not excavate dark material but show bright ejecta. The surface coverage of diffuse dark material is largest east and south of Calpurnia.

\section{Distribution of dark material}

The dark material is distributed unevenly across Vesta's surface. Clustering occurs for all types of dark material exposure, and some craters expose or are associated with dark material in contrast to others in the immediate vicinity. This indicates local concentrations in the subsurface, rather than widespread subsurface strata of dark material.

The densest concentration of dark material occurs east, west and south of the Marcia-Calpurnia-Minucia impact structures about $127-218^{\circ} \mathrm{E}$ and about $21^{\circ} \mathrm{S}-30^{\circ} \mathrm{N}$ (Fig. 1 ). Another dense concentration is located at $100-155^{\circ} \mathrm{E}$ and $12-50^{\circ} \mathrm{S}$ (Fig. 1).

All other dark material exposures are more or less isolated deposits correlated with impact craters: as small outcrops or incorporated in the ejecta or elongated dark features excavated by small impacts. The local characteristics of dark material, which clearly separates it from areas without dark material, as well as the uneven distribution across the surface of Vesta, suggest a distribution process that focuses on the deposition of small amounts of material rather than global coverage. On a global scale the densest 
concentrations of dark material, outcrops as well as subsurface patches, appear to be correlated with the northern and northwestern rim of the Veneneia south polar basin (Jaumann et al., 2012b; Otto et al., 2012; Reddy et al., 2012), extending about $130 \mathrm{~km}$ inside as well as outside the rim structure (Fig. 1). Marcia is located about $100 \mathrm{~km}$ north of the Veneneia rim, and it is in this region that much of the dark material is concentrated (Fig. 1). On the opposite, northeastern side, Veneneia is bordered by Vestalia Terra, the highest elevated region on Vesta (Fig. 1). At the northern part of Vestalia Terra at lower elevations, large impacts such as Numisia, Drusilla, Cornelia and an unnamed crater at $228.8^{\circ} \mathrm{E}$ and $1.4^{\circ} \mathrm{N}$ have dark outcrops and ejecta. These craters are $\sim 200 \mathrm{~km}$ away from the Veneneia rim and have diameters of $15-30 \mathrm{~km}$, with the smallest of them, Cornelia, being the closest to the rim.

A large, subdued circular feature of $180 \mathrm{~km}$ in diameter in this area centered at $\sim 245^{\circ} \mathrm{E}$ and $30^{\circ} \mathrm{S}$ could be an old basin. The dark material excavated by the craters may also be associated with the rim and ejecta of such a basin. Dark material outside these two regions is rare and, compared to the size of the impacts, is exposed only as small spots.

\section{Discussion of the geological context of dark material}

\subsection{Indication for the subsurface structure of dark material}

Although there are small albedo variations in the Vestan regolith all appearances of dark material, which differ by more than $10 \%$ from the surrounding albedo on Vesta are correlated with impact structures in crater walls as well as in the ejecta, suggesting excavation of this material from the subsurface. In particular, craters $>18 \mathrm{~km}$ exhibit dark material in the walls and in the ejecta that is closely correlated with wall outcrops. The correlation of dark outcrops and dark ejecta in specific parts of the crater while other parts of the crater wall and ejecta are completely free of dark material indicate the presence of discontinuous dark layers or patches in the subsurface. In addition, impacts that have dark ejecta only on one side of the crater may have excavated a dark/non-dark material boundary, indicating non-continuous, relatively small subsurface patches of dark material.

Small impacts in the vicinity of larger craters with dark outcrops do not have dark material in their ejecta. Therefore, a certain impact size is needed to penetrate to the depth of the dark layer
(Fig. 17). Dark outcrops occur in the first $2000 \mathrm{~m}$ beneath the crater rim. However, the depth of the dark outcrops varies among different craters, between depths of $200 \mathrm{~m}$ and $2000 \mathrm{~m}$. In some areas (e.g., Marcia) more than one layer of dark outcrops are exposed. This might be due to distinct layers at different depths, or to a tilt of the layer. Rough estimates of the thickness of the outcrops indicate less than $100 \mathrm{~m}$ for a single layer.

The different depths of the dark material layers may be due to subsequent re-exposure and re-burying by ejecta of multiple impacts (Fig. 18). A layer of dark material excavated by a large impact results patches of dark material in its ejecta. Ejecta of nearby impacts that is free of dark material covers these dark patches. Subsequent smaller impacts into the extended ejecta sheets with intermixed dark patches of the former larger impacts re-excavated the dark material. A repetition of this process will produce different layers of dark patches at different levels in the subsurface (Fig. 18).

This mixing process will build up a complex interlayering of dark material and non-dark regolith with the dark material being restricted to relatively small patches in the subsurface on Vesta. Dark patches within crater ejecta might either be due to local concentrations supported either by density and/or particle size differences in the ejecta plume, or to the accumulation of ejecta in front of obstacles (e.g., large boulders), suggesting that the dark material has been excavated late in the cratering process. Dark material in the ejecta blanket also explains the dark regions originating directly from the crater rim as an accumulation of ejected dark material close to the rim that falls back into the crater by mass wasting. Smaller craters with continuous ejecta composed of dark material (similar to lunar dark-halo impact craters) indicate that a dark subsurface layer exists in the target site. In some cases, craters exhibit dark ejecta just on one side, indicating that the crater straddles a subsurface boundary between dark material and an uncontaminated Vesta lithology. Dark rays and dark swirls emanating from some craters suggest that only very small patches (much less than the crater size) in the subsurface have actually been mixed into the ejected material.

In general, outcrops and ejecta of dark material and their surface and subsurface distribution are limited in size. Layers cropping out are a few hundred meters to a few kilometers wide and less than $100 \mathrm{~m}$ thick. Dark halo ejecta is restricted to craters $<3 \mathrm{~km}$ and cover surface areas of about $20 \mathrm{~km}^{2}$ or less. Areas where

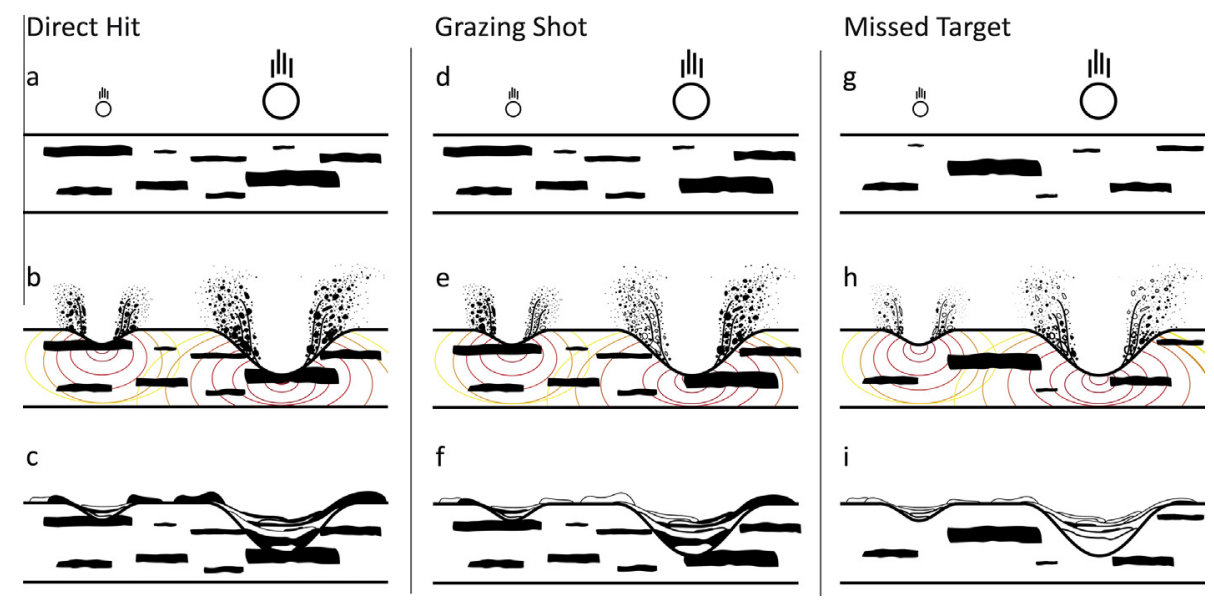

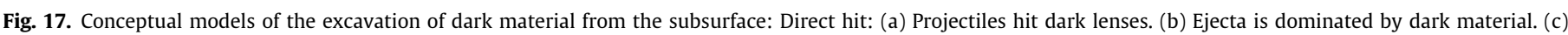

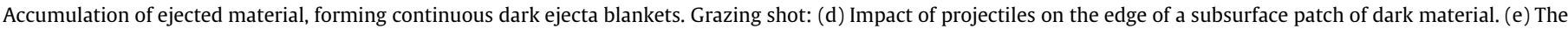

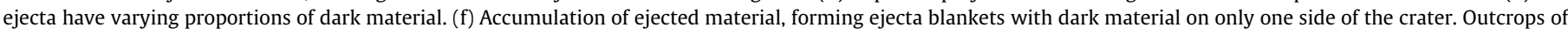

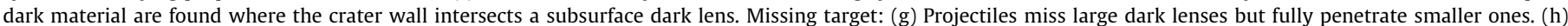

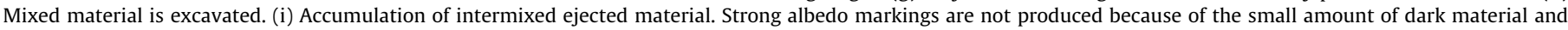
efficient mixing with the non-dark regolith. 


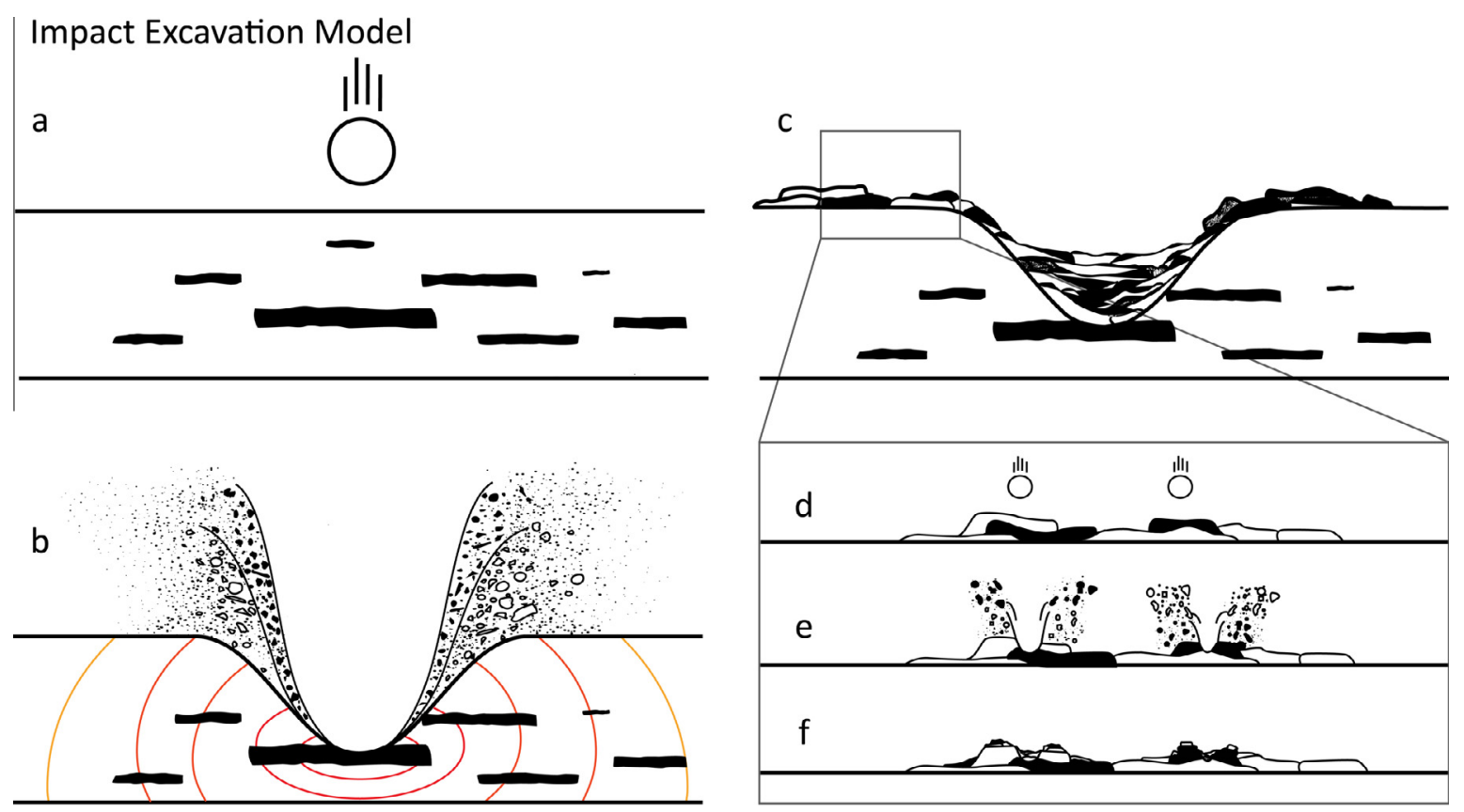

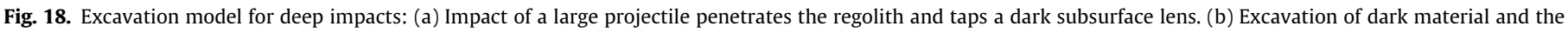

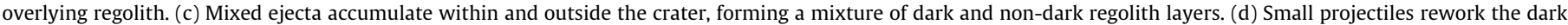

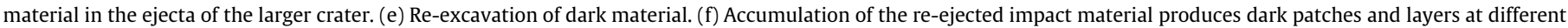
levels in the subsurface.

small impacts reveal subsurface dark layers cover a few to a few hundred square kilometers.

\subsection{Diffuse distribution of dark material}

The only large area covered by dark material is the surface east of the Calpurnia and Marcia impacts (Fig. 1). This area measures about $11,000 \mathrm{~km}^{2}$ in size and extends from $196^{\circ} \mathrm{E}$ to $218^{\circ} \mathrm{E}$ and $18^{\circ} \mathrm{N}$ to $7^{\circ} \mathrm{S}$. The distribution and surface coverage in this area indicate a diffuse deposition of the material on the surface by a widespread ballistic process. This interpretation is consistent with the fact that dark material accumulates in front of obstacles such as the rims of smaller impact craters and hills. The dark material completely surrounds Calpurnia from north to east and south. However, the southwestern part where Marcia is superimposed on Calpurnia and its ejecta is much brighter. The dark surface area surrounding Calpurnia extends all the way to the crater rim, identifying this dark material as Calpurnia ejecta. A possible scenario is that the Calpurnia crater impacted a dark layer of considerable size and deposited dark material intermixed into the ejecta all around Calpurnia. The younger and larger impact Marcia hit the southwestern ejecta blanket of Calpurnia as well as the subsurface dark layer. Marcia is about 30\% larger than Calpurnia and, due to its wider north to south dimension (about 20\%) appears to have resulted from a somewhat oblique impact. Marcia is about twice as deep as Calpurnia, suggesting that the Marcia impact might have mixed the dark layer with a large portion of material excavated from beneath the layer, diluting the dark material layer. In addition, the slightly oblique impact might have distributed the Marcia ejecta preferentially to the south and west, overlying the dark ejecta from Calpurnia. East of Calpurnia the topography raises by about $7000 \mathrm{~m}$ towards Vestalia Terra, while west and southwest of Calpurnia the plains are at the same elevation. Thus, Vestalia Terra forms a barrier where the Calpurnia ejecta (including the dark material) accumulated, while to the west the ejecta are distributed over a much larger area. Scattered more widely, the dark material per unit ejecta is less concentrated and more evenly mixed with non-dark ejecta. The more recent Marcia impact destroyed and covered the Calpurnia ejecta in this region. Moreover, it cannot be ruled out that Calpurnia formed on a boundary between dark and non-dark material, and that its eastern ejecta contained a greater proportion of dark material than does the southwestern part.

\subsection{Geological evidence for the origin of dark material}

All surface exposures of dark material are correlated with impact excavation processes indicating dark material to be part of Vesta's subsurface. Geological analyses demonstrate that the dark subsurface layers are close to the surface, relatively thin, and expressed as isolated patches. In principle, two processes are expected to account for such an observation: volcanic deposits or low-velocity impacts implanting dark impactor material into the upper regolith (Jaumann et al., 2012b; McCord et al., 2012).

Volcanic features and products were expected on the surface of Vesta because Vesta is similar in composition to the howarditeeucrite-diogenite (HED) family of basaltic achondrite meteorites, as determined from laboratory studies (e.g., McCord et al., 1970; Feierberg et al., 1980; Gaffey, 1997; Binzel et al., 1997; Cochran and Vilas, 1998). Furthermore, mathematical modeling (Wilson and Keil, 1996, 1997) predicted specific types and dimensions of volcanic deposits that might be found on Vesta, such as surface lava flows up to tens of meters thick, a few hundred meters to a few kilometers wide, and a few kilometers to several tens of kilometers long; channelized flows on steeper slopes and no uniform sheet flows or shield volcanoes; shallow dikes of $\sim 1 \mathrm{~m}$ wide and vertical extents of $<10 \mathrm{~km}$, deeper dikes with thicknesses $\leqslant 3 \mathrm{~m}$ and lateral extents $\leqslant 30 \mathrm{~km}$; and only localized pyroclastic fall deposits derived from optically-dense lava fountains that form lava ponds feeding lava flows. However, no unambiguous volcanic deposits have been identified in Dawn observations (Jaumann et al., 2012a). This is consistent with theoretical simulations of a Vesta magma ocean that might be to shallow and to short-lived to leave any traces in the uppermost crust and on the surface 


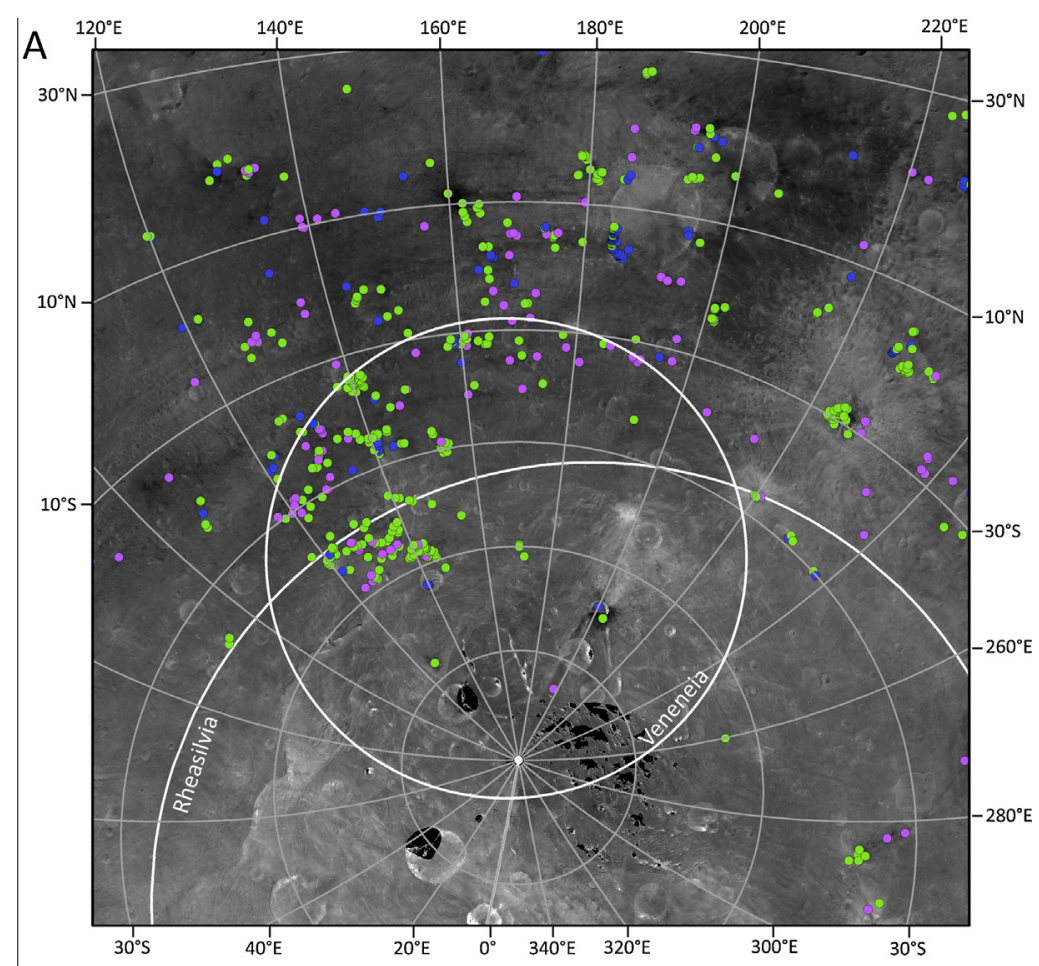

Classification of dark material geological settings

- Material cropping out at crater walls, scarps and escarpments (class 1)

- Material on crater rims in ejecta or mass wasting deposits (class 2)

- Dark regolith and linear dark features (class 3)

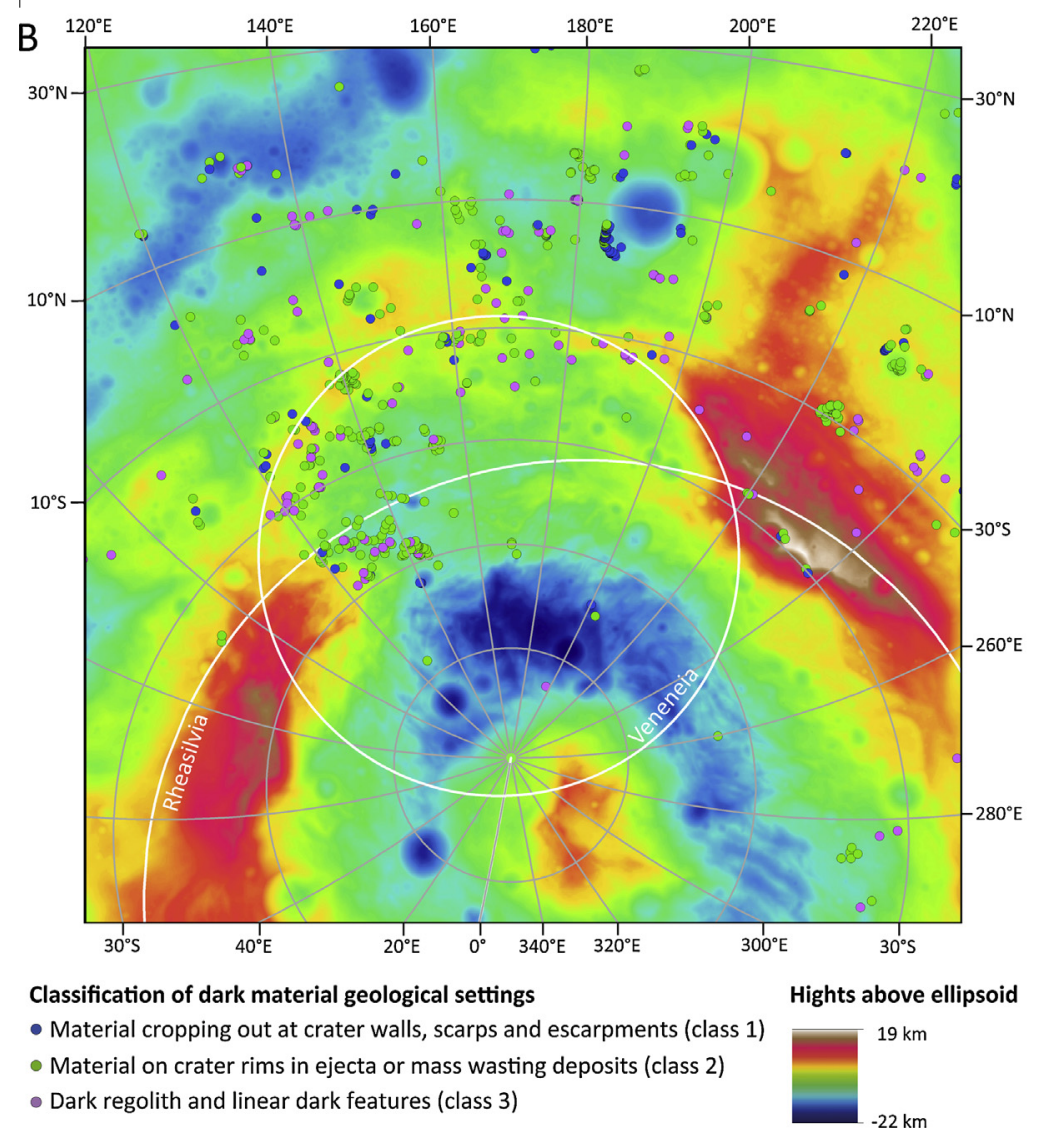

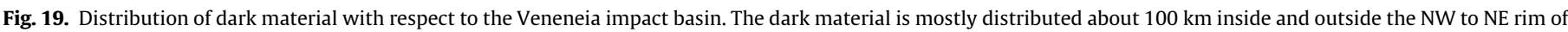
Veneneia. (Data base: (A) HAMO photometric corrected (resolution $60 \mathrm{~m} / \mathrm{pxl}$ ); (B) HAMO DTM color coded (resolution $\sim 92 \mathrm{~m} /$ pixel.) 
(Neumann et al., 2014). All features with lobate, lava flow-like morphologies occur in close proximity to impact craters or topographic elevations, which are best interpreted as gravity-driven mass flow deposits, impact ejecta deposits, or impact melt deposits. None of the dark material deposits correlate with volcanic deposits as proposed by Wilson and Keil, 1996, 1997. Furthermore, the spectral signature of dark material is almost identical with that of the surrounding Vesta regolith, only the albedo and thus the absorption depth of the two pyroxene bands at 1 and $2 \mu \mathrm{m}$ are reduced with no variations of the band centers (McCord et al., 2012; Stephan et al., 2014; Palomba et al., 2014). This also suggests that dark material does not resemble pure volcanic deposits, but rather is a component that acts solely to reduce the albedo. Carbonaceous chondrites have a very low albedo and may be considered as the leading candidate for the darkening agents. In addition, dark deposits listed in the VIR catalog show an increased $\mathrm{OH}$ absorption feature as the albedo decreases (Palomba et al., 2014), in agreement with the behavior retrieved for the two broad low albedo areas found by De Sanctis et al. (2012b). One may assume that low-velocity impacts (O'Brien et al., 2011; Reddy et al., 2012) that are likely to occur on Vesta will have preserved parts of the impactor material that has subsequently been distributed across the surface.

The fact that almost all dark material is concentrated in the upper $2000 \mathrm{~m}$ of the subsurface and that even large impacts do not excavate any deeper layers also suggests an exogenic rather than a deep-seated endogenic origin. Apart from the extended dark deposit east of the large craters Marcia and Calpurnia, all exposures
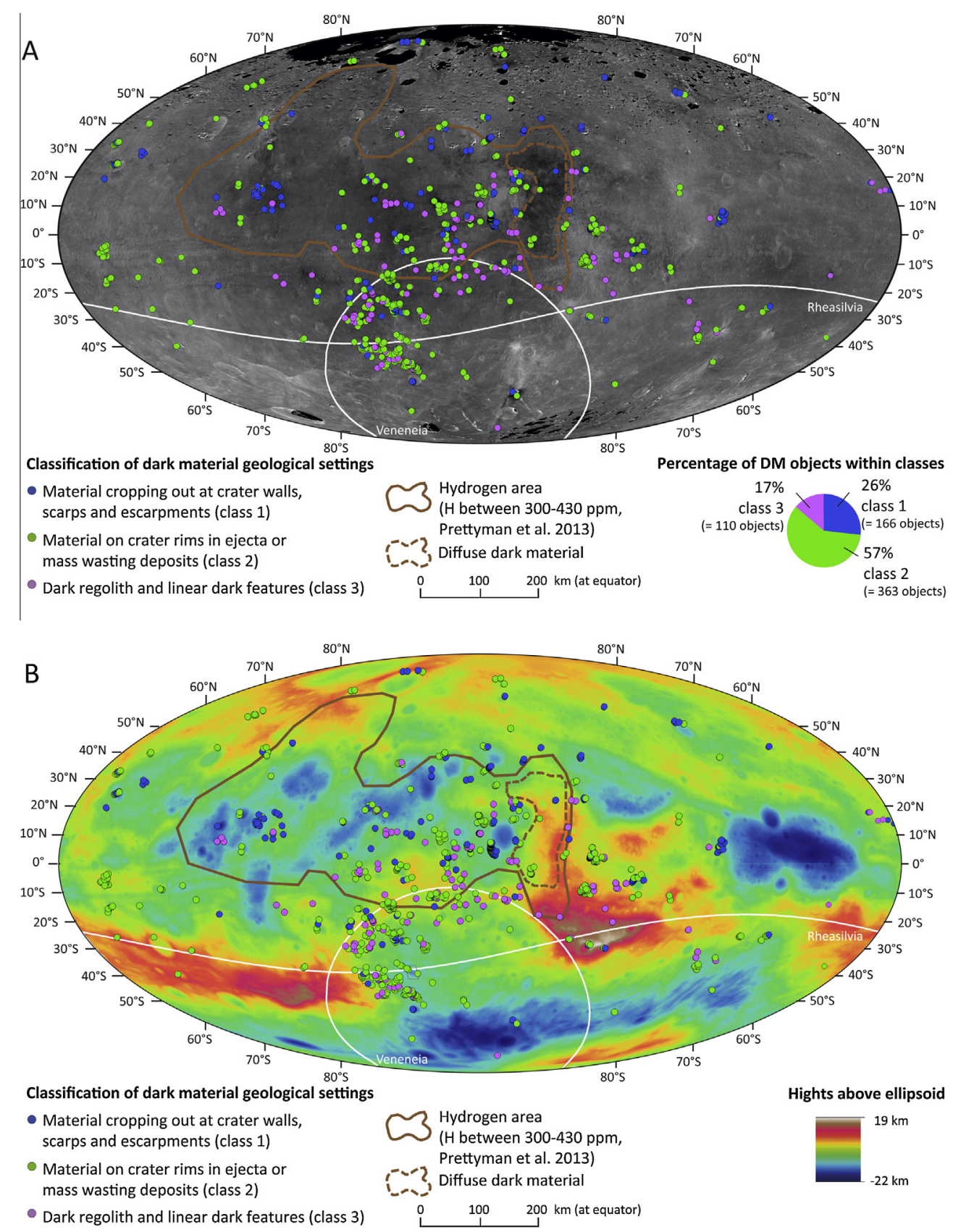

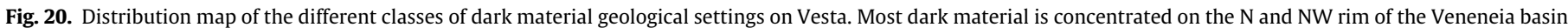

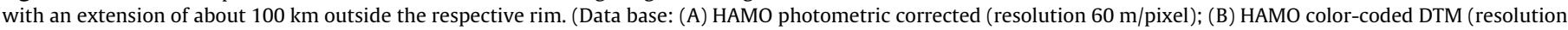
$\sim 92 \mathrm{~m} /$ pixel).) 
of dark material are small dark spots correlated with outcrops in either crater walls or ejecta. If we assume the dark material to have been delivered to the surface of Vesta by numerous medium sized to small impacts producing craters $<30 \mathrm{~km}$ throughout the history of Vesta, we would expect to see a more or less even distribution of dark patches. However, dark material is mostly concentrated about $100 \mathrm{~km}$ inside and outside the northwestern to northeastern rim of the Veneneia impact basin (Fig. 19). Such a regional concentration associated with a large basin suggests a direct link between the impact and the deposition of dark material. Assuming that a lowvelocity impact ( $<2 \mathrm{~km} / \mathrm{s}$ ) has created the $450 \mathrm{~km}$ Veneneia crater, most of the projectile, about $50 \mathrm{~km}$ in diameter, would have survived. The impactor material would have fallen back into the crater and would be concentrated in the nearby ejecta, while far less of the material was distributed globally (Reddy et al., 2012). This is consistent with observed the distribution of dark material on Vesta's surface. The reason that dark material is presently concentrated in the northern part of Veneneia is that the more recent Rheasilvia impact destroyed the southern rim of Veneneia, excavated all of the local dark deposits and mixed them with the non-dark ejecta. A few dark deposits are visible in the northeastern rim of Rheasilvia. These might be residuals of dark material from the southern rim of Veneneia. Contributions to the dark material deposits from other, much older large basins cannot be excluded. The current discussion of a possible existence of subdued old large basins in the area northeast of Vestalia Terra might identify such a contributor. Then again, the dark material in these regions is still close enough to explain these deposits as originating from Veneneia, covered by Rheasivila ejecta and exposed by larger impacts such as Numisia, Drusila and Cornelia.

Another argument for the correlation of dark material and Veneneia is the concentration of $\mathrm{H}$ and $\mathrm{OH}$, which corresponds to that of the broader dark areas (Prettyman et al., 2012; McCord et al., 2012; De Sanctis et al., 2012b; Reddy et al., 2012) (Figs. 19 and 20). Carbonaceous chondritic impactors can contain 10-20\% $\mathrm{OH}$-bearing hydrated minerals in addition to carbonaceous compounds.

\section{Summary and conclusions}

We identified $\sim 500$ impact craters with dark material exposed in their walls and rims (Figs. 19 and 20). Most of these exposures have the same geological characteristics: (1) Outcrops appear within the first $2000 \mathrm{~m}$ below the rim. (2) In most cases outcrops are correlated with a spur and gully modification of the crater walls. (3) Spurs are composed of bright competent material, whereas the dark material emanates from the less competent gully alcoves. (4) Partly, fans of bright material overlay dark ones and vice versa. (5) Dark outcrops are thin small layers of restricted lateral extent, ranging from single spots (a few tens of meters) to short layers of a few kilometers. They are disconnected and separated by areas within the crater wall that are of dark material-free. (6) Material accumulating on the crater floor shows a higher albedo than the dark outcrops but lower than the average surrounding regolith, indicating mixing of mass wasting material with dark components. (7) In some cases the dark material covers the rim above the dark outcrop, darkens the ejecta adjacent to the outcrops and appears as dark swirl-like striation emanating from the outcrops outside of the crater. (8) In some cases the dark ejecta only occurs on one side of the crater. (9) Dark areas that are not directly correlated with larger craters show very small impacts $(<1 \mathrm{~km})$, excavating and distributing dark material within limited surface regions.

Among the three types of dark components found in howardite-eucrite-diogenite meteorites (Russell et al., 2012) which include clasts of carbonaceous chondritic material, impact melt and impact shock-blackened material (McSween et al., 2011, 2013), the carbonaceous component provides the best match with the spectral properties (McCord et al., 2012) and in almost all cases with the geological setting and the subsurface structure of the dark material.

\section{Acknowledgments}

The success of the Dawn mission is due to the efforts of a large team of engineers, scientists, and administrators in industry and government laboratories both in the United States and abroad. The Dawn mission is managed by NASA's Jet Propulsion Laboratory, a division of the California Institute of Technology in Pasadena, for NASA's Science Mission Directorate, Washington, DC. UCLA is responsible for overall Dawn mission science. The Dawn Framing Cameras have been developed and built under the leadership of the Max Planck Institute for Solar System Research, Katlenburg-Lindau, Germany, with significant contributions by DLR German Aerospace Center; Institute of Planetary Research, Berlin; and in coordination with the Institute of Computer and Communication Network Engineering, Braunschweig. The framing camera project is funded by DLR, the Max Planck Society, and NASA/JPL. VIR has been developed under the leadership of INAF-Istituto di Astrofisica e Planetologia Spaziali, Rome, Italy and is funded by AeroDynamic Solutions, the Italian Space Agency. Several of the co-authors are supported by NASA's Dawn at Vesta Participating Scientist program, DLR, the German Space Agency and ASI, the Italian Space Agency. We thank the Dawn team for the development, cruise, Dawn orbital insertion, and operations of the Dawn spacecraft at Vesta. We thank Elke Kersten and Tanja Giebner for supporting the preparation of maps and sketches. We also like to thank Matt Balme and an anonymous reviewer for their constructive comments. Dawn data are archived with the NASA Planetary Data System. The data used in this paper are available from the website http://dawndata.igpp.ucla.edu.

\section{References}

Archinal, B.A. et al. 2011. Report of the IAU working group on cartographic coordinates and rotational elements: 2009. Celest. Mech. Dynam. Astron. 109, $101-135$

Binzel, R.P., Gaffey, M.J., Thomas, P.C., Zellner, B.H., Storrs, A.D., Wells, E.N., 1997. Geologic mapping of Vesta from 1994 Hubble Space Telescope images. Icarus 128, 95-103.

Capria, M.T. et al., 2014. Vesta surface thermal properties map. Geophys. Res. Lett. 41, 1438-1443.

Cloutis, E.A., Izawa, M.R.M., Pompilio, L., Reddy, V., Hiesinger, H., Nathues, A., Mann, P., Le Corre, L., Palomba, E., Bell III, J.F., 2013. Spectral reflectance properties of HED meteorites + CM2 carbonaceous chondrites: Comparison to HED grain size and compositional variations and implications for the nature of low-albedo features on Asteroid 4 Vesta. Icarus 223, 850-877.

Cochran, A.L., Vilas, F., 1998. The changing spectrum of Vesta: Rotationally resolved spectroscopy of pyroxene on the surface. Icarus 134, 207-212.

Croft, S.K., 1981. Relationships between the apparent crater, transient crater and excavation cavity of a simple crater. In: James, O.B., Hörz, F. (Eds.), Workshop on Apollo 16. LPI Technical Report 81-01. Lunar and Planetary Institute, p. 40.

De Sanctis, M.C. et al., 2010. The VIR spectrometer. Space Sci. Rev. 163, 329-369.

De Sanctis, M.C. et al., 2012a. Spectroscopic characterization of mineralogy and its diversity across Vesta. Science 336, 697-700.

De Sanctis, M.C. et al., 2012b. Detection of widespread hydrated materials on Vesta by VIR imaging spectrometer on board the Dawn mission. Astrophys. J. 758: L36, 1-5.

De Sanctis, M.C. et al., 2013. Vesta's mineralogical composition as revealed by VIR on Dawn. Meteorit. Planet. Sci. 48, 1-19.

Denevi, B.W. et al., 2012. Pitted terrain on Vesta and implications for the presence of volatiles. Science 338, 246-249.

Feierberg, M.A., Larson, H.P., Fink, U., Smith, H.A., 1980. Spectroscopic evidence for two achondrite parent bodies: Asteroids 349 Dembowska and 4 Vesta. Geochim. Cosmochim. Acta 44, 513-524.

Gaffey, M.J., 1997. Surface lithologic heterogeneity of Asteroid 4 Vesta. Icarus 127 130-157.

Gwinner, K. et al., 2009. Derivation and validation of high-resolution digital terrain models from Mars Express HRSC data. Photogr. Eng. Rem. Sens. 75, 1127-1142. 
Herrin, J.S., Zolensky, M.E., Cartwright, J.A., Mittlefehldt, D.W., Ross, D.K., 2011. Carbonaceous chondrite-rich howardites, the potential for hydrous lithologies on the HED parent. Lunar Planet. Sci. 42. Abstract 2806.

Jaumann, R. et al., 2007. The High-Resolution Stereo Camera (HRSC) experiment on Mars Express: Instrument aspects and experiment conduct from interplanetary cruise through the nominal mission. Planet. Space Sci. 55, 928-952.

Jaumann, R. et al., 2012a. Vesta's shape and morphology. Science 336, 687-690.

Jaumann, R. et al., 2012b. The geologic context of Vesta's dark material. American Geophysical Union 2012. Abstract P43E-02.

Kaasalainen, M., Torppa, J., Muinonen, K., 2001. Optimization methods for asteroid lightcurve inversion. II. The complete inverse problem. Icarus 153, 37-51.

Krohn, K. et al., 2014. Asymmetric craters on Vesta: Impact on sloping surfaces. Planet. Space Sci., in press. http://dx.doi.org/10.1016/j.pss.2014.04.011.

Li, J.-Y., 2013. Body-fixed Coordinate Systems for Asteroid (4) Vesta. <sbn.psi.edu/ archive/dawn/fc/DWNVFC2_1A/DOCUMENT/VESTA_COORDINATES/ VESTA COORDINATES 131018.PDF>.

Li, J.-Y., Le Corre, L., Schröder, S.E., Reddy, V., Denevi, B.W., Buratti, B., Mottola, S., Hoffmann, , Gutierrez-Marques, P., Nathues, A., Russell, C.T., Raymond, C.A., 2013. Global photometric properties of Asteroid (4) Vesta observed with Dawn Framing Camera. Icarus 226, 1252-1274.

Lorenz, K.A., Nazarov, M.A., Kurat, G., Brandstaetter, F., Ntaflos, T., 2007. Foreign meteoritic material of howardites and polymict eucrites. Petrology 15, 109125.

McCord, T.B., Adams, J.B., Johnson, T.V., 1970. Asteroid Vesta: Spectral reflectivity and compositional implications. Science 168, 1445-1447.

McCord, T.B. et al., 2012. Dark material on Vesta from the infall of carbonaceous volatile-rich material. Nature 491, 83-86.

McCoy, T., Reynolds, V., 2007. PRA 0440, PRA 04402. Antarctic Meteorite Newsletter 30,1

McSween, H.Y., Mittlefehldt, D.W., Beck, A.W., Mayne, R.G., McCoy, T.J., 2011. HED meteorites and their relationship to the geology of Vesta and the Dawn mission. Space Sci. Rev. 163, 141-174.

McSween, H.Y et al, 2013. Dawn; the Vesta-HED connection; and the geologic context for eucrites, diogenites, and howardites. Meteorit. Planet. Sci. 48, 20902104.

Melosh, H.J., 1989. Impact Cratering: A Geologic Process. Oxford University Press.

Neumann, W. Breuer, D., Spohn, T., 2014. Differentiation of Vesta: Implications for shallow magma ocean. Earth Planet. Sci. Lett. 395, 267-280.

O’Brien, D.P., Sykes, M.V., Tricarico, P., 2011. Collision probabilities and impact velocity distributions for Vesta and Ceres. Lunar Planet. Sci. 42. Abstract 2665.

Osinski, R.G., Pierazzo, E., 2013. Impact Cratering: Processes and Products. WileyBlackwell, pp. 2-16.

Otto, K. et al., 2012. The morphology and Albedo of dark material on Vesta. EPSC 2012. Abstract 629.

Palomba, E., Longobardo, A., De Sanctis, C.M., Zambon, F., Tosi, F., Ammannito, E. Capaccioni, F., Frigeri, A., Capria, M.T., Cloutis, E.A., Jaumann, R., Combe, J.P., Raymond, C.A., Russell, C.T., 2014. Composition and mineralogy of dark material units on Vesta. Icarus, this issue.

Prettyman, T.H. et al., 2011. Dawn's Gamma Ray and Neutron Detector. Space Sci. Rev. 163, 371-459.

Prettyman, T.H. et al., 2012. Elemental mapping by Dawn reveals exogenic $\mathrm{H}$ in Vesta's regolith. Science 338, 242-246.

Preusker, F. et al., 2011. Stereo topographic models of Mercury after three MESSENGER flybys. Planet. Space Sci. 59, 1910-1917.

Preusker, F. et al., 2012. Stereo-photogrammetrically derived topography of Asteroid (4) Vesta. American Geophysical Union 2012, P43E-05.
Raymond, C.A. et al., 2011. The Dawn topography investigation. Space Sci. Rev. 163. 487-510.

Reddy, V., Le Corre, L., O’Brien, D.P., Nathues, A., Cloutis, E.A., Durda, D.D., Bottke, W.F., Bhatt, M.U., Nesvorny, D., Buczkowski, D., Scully, J.E.C., Palmer, E.M., Sierks, H., Mann, PJ., Becker, K.J., Beck, A.W., Mittlefehldt, D., Li, J.-Y., Gaskell, R. Russell, C.T., Gaffey, M.J., McSween, H.Y., McCord, T.B., Combe, J.-P., Blewett, D., 2012. Delivery of dark material to Vesta via carbonaceous chondritic impacts. Icarus 221, 544-559.

Roatsch, T. et al., 2012. High resolution Vesta High Altitude Mapping Orbit (HAMO) Atlas derived from Dawn Framing Camera images. Planet. Space Sci. 73, 283286.

Russell, C.T., Raymond, C.A., 2011. The Dawn mission to Vesta and Ceres. Space Sci. Rev. 163, 3-23.

Russell, C.T. et al., 2012. Dawn at Vesta: Testing the protoplanetary paradigm. Science 336, 684-686.

Russell, C.T. et al., 2013. Dawn completes its mission at 4 Vesta. Meteorit. Planet. Sci., $1-14$.

Schröder, S.E., Maue, T., Gutiérrez Marqués, P., Mottola, S., Aye, K.M., Sierks, H., Keller, H.U., Nathues, A., 2013a. In-flight calibration of the Dawn Framing Camera. Icarus 226, 1304-1317.

Schröder, S.E., Mottola, S., Keller, H.U., Raymond, C.A., Russell, C.T., 2013b. Resolved photometry of Vesta reveals physical properties of crater regolith. Planet. Space Sci. 85, 198-213.

Shkuratov, Y., Kaydash, V., Korokhin, V., Velikodsky, Y., Opanasenko, N., Videen, G., 2011. Optical measurements of the Moon as a tool to study its surface. Planet. Space Sci. 59, 1326-1371.

Sierks, H. et al., 2011. The Dawn Framing Camera. Space Sci. Rev. 163, 263-327.

Stephan, K. et al., 2014. Small fresh impact craters on asteroid 4 Vesta: A compositional and geological fingerprint. J. Geophys. Res. Planets, 2169-9100. http://dx.doi.org/10.1002/2013JE004388.

Vincent, J.-B. et al., 2012a. Crater depth-to-diameter ratio and surface properties of (4) Vesta. Lunar Planet. Sci. 43. Abstract 1415

Vincent, J.-B., Besse, S., Marchi, S., Sierks, H., Massironi, M.OSIRIS Team, 2012b. Physical properties of craters on Asteroid (21) Lutetia. Planet. Space Sci. 66, 7986.

Williams, D.A. et al., 2014. The geology of the Marcia quadrangle of Asteroid Vesta: Assessing the effects of large, young craters. Icarus, this issue. http://dx.doi.org/ 10.1016/j.icarus.2014.01.033.

Williams, D.A. et al., 2013. Lobate and flow-like features on Asteroid Vesta. Planet. Space Sci., in press. http://dx.doi.org/10.1016/j.pss.2013.06.017.

Williams, D.A., Yingst, R.A., Garry, W.B., 2014. Introduction: The geologic mapping of Vesta. Icarus, in press. http://dx.doi.org/10.1016/j.icarus.2014.03.001.

Wilson, L., Keil, K., 1996. Volcanic eruptions and intrusions on the Asteroid 4 Vesta. J. Geophys. Res. - Planets 101, 18927-18940.

Wilson, L., Keil, K., 1997. The fate of pyroclasts produced in explosive eruptions on the Asteroid 4 Vesta. Meteorit. Planet. Sci. 32, 813-824.

Yingst, A. et al., 2014. Geologic mapping of Vesta. Planet. Space Sci., in press.

Zellner, B.H., Albrecht, R., Binzel, R.P., Gaffey, M.J., Thomas, P.C., Storrs, A.D., Wells, E.N., 1997. Hubble Space Telescope images of Asteroid 4 Vesta in 1994. Icarus $128,83-87$.

Zolensky, M.E., Weisberg, M.K., Buchanan, P.C., Mittlefehldt, D.W., 1996. Mineralogy of carbonaceous chondrite clasts in HED achondrites and the Moon. Meteorit. Planet. Sci. 31, 518-537.

Zuber, M.T. et al., 2011. Origin, internal structure and evolution of 4 Vesta. Space Sci. Rev. 163, 77-94. 